OPEN ACCESS

Edited by: Maria Pia Felli,

Sapienza University of Rome, Italy

Reviewed by:

Tomomi Toubai,

Yamagata University, Japan

Lisa M. Minter,

University of Massachusetts Amherst

United States

*Correspondence:

Ivan Maillard

imaillar@pennmedicine.upenn.edu

Specialty section:

This article was submitted to

Signaling,

a section of the journal

Frontiers in Cell and Developmental

Biology

Received: 04 January 2021

Accepted: 26 April 2021

Published: 28 May 2021

Citation:

Allen F and Maillard I (2021) Therapeutic Targeting of Notch

Signaling: From Cancer

to Inflammatory Disorders.

Front. Cell Dev. Biol. 9:649205.

doi: 10.3389/fcell.2021.649205

\section{Therapeutic Targeting of Notch Signaling: From Cancer to Inflammatory Disorders}

\author{
Frederick Allen ${ }^{1,2}$ and Ivan Maillard ${ }^{1,2 *}$ \\ ${ }^{1}$ Division of Hematology and Oncology, Department of Medicine, Perelman School of Medicine at the University \\ of Pennsylvania, Philadelphia, PA, United States, ${ }^{2}$ Abramson Family Cancer Research Institute, Perelman School \\ of Medicine at the University of Pennsylvania, Philadelphia, PA, United States
}

Over the past two decades, the Notch signaling pathway has been investigated as a therapeutic target for the treatment of cancers, and more recently in the context of immune and inflammatory disorders. Notch is an evolutionary conserved pathway found in all metazoans that is critical for proper embryonic development and for the postnatal maintenance of selected tissues. Through cell-to-cell contacts, Notch orchestrates cell fate decisions and differentiation in non-hematopoietic and hematopoietic cell types, regulates immune cell development, and is integral to shaping the amplitude as well as the quality of different types of immune responses. Depriving some cancer types of Notch signals has been shown in preclinical studies to stunt tumor growth, consistent with an oncogenic function of Notch signaling. In addition, therapeutically antagonizing Notch signals showed preclinical potential to prevent or reverse inflammatory disorders, including autoimmune diseases, allergic inflammation and immune complications of life-saving procedures such allogeneic bone marrow and solid organ transplantation (graft-versus-host disease and graft rejection). In this review, we discuss some of these unique approaches, along with the successes and challenges encountered so far to target Notch signaling in preclinical and early clinical studies. Our goal is to emphasize lessons learned to provide guidance about emerging strategies of Notchbased therapeutics that could be deployed safely and efficiently in patients with immune and inflammatory disorders.

Keywords: Notch, Notch ligands, immune system, inflammation, cancer

\section{INTRODUCTION}

Inflammation is a dynamic process mobilizing multiple cell types and mediators in response to stimuli that are perceived as harmful. The Notch signaling pathway is emerging as a critical regulator of inflammation, with pathogenic roles in several inflammatory and immune disorders including autoimmunity and allergic airway inflammation. In addition, Notch critically regulates graft-versus-host disease (GVHD) and graft rejection, the major complications mediated by immune responses to foreign tissue antigens after life-saving transplantation procedures, such as transplantation of allogeneic bone marrow or solid organ allografts. Therapeutic strategies to inhibit Notch signaling have first been developed preclinically and in early phase clinical trials to target oncogenic functions of the Notch pathway in tumor cells, or in tumor angiogenesis. However, 
many of these strategies are now also actively investigated in preclinical settings for their therapeutic value in non-malignant inflammatory disorders.

In this review, we discuss emerging concepts about the effects of Notch signaling in the regulation of mature immune cell function, beyond the role of the Notch pathway that was first established in immune cell development (Osborne and Minter, 2007; Radtke et al., 2010; Yuan et al., 2010; Brandstadter and Maillard, 2019). First, we outline unique molecular features of the Notch pathway that underlie the most promising therapeutic strategies to inhibit Notch activation. We discuss the oncogenic functions of Notch signaling that first inspired an intense interest in therapeutic targeting of Notch signaling, with a special focus on lessons learned from the successes and challenges of preclinical and early clinical investigations of Notch inhibition in cancer. We then review a growing body of work uncovering profound effects of Notch signaling in nonmalignant inflammatory disorders, including immune disorders with high relevance to human disease. Specific Notch ligands and receptors play dominant functions in the interaction of immune cells with their microenvironment, opening therapeutic perspectives based on their transient targeted inhibition at sensitive stages of immune cell differentiation and function. Integrating lessons learned in cancer therapeutics and in preclinical studies of Notch signaling in the immune system, we will discuss emerging concepts that could pave the way toward effective development of Notch-based therapeutic strategies in non-malignant inflammatory disorders.

\section{MECHANISMS AND FUNCTION OF NOTCH SIGNALING}

A Notch-related phenotype was first described by John Dexter and Thomas Morgan more than a century ago, based on inherited changes that looked like "notches" at the wing margin of Drosophila melanogaster fruit flies (Dexter, 1914; Morgan, 1917). Since the fly Notch gene was cloned in 1983, the Notch signaling pathway has emerged as an essential evolutionarily conserved pathway for the development of all metazoans (Artavanis-Tsakonas et al., 1983). Notch is important for directing cell-to-cell communication and cell fate decisions throughout embryogenesis and into postnatal life, where Notch helps maintain homeostasis of selected tissues. However, Notch has unique characteristics that distinguish it from other evolutionarily conserved pathways. First, activation of Notch signaling is enacted in trans between adjacent cells (Figure 1). Second, canonical Notch signaling does not rely on signal amplification from second messengers to enact its functions, because its cleaved intracellular domain can translocate to the nucleus in order to stimulate gene transcription, before being rapidly degraded (Kopan and Ilagan, 2009; Kovall et al., 2017). These features enable careful temporal and spatial regulation of Notch signaling intensity.

In mammals, five Notch ligands interact with four Notch receptors (Notch1-4), referred to as Notch ligand or receptor "paralogs" (Ellisen et al., 1991; Weinmaster et al., 1992; del Amo et al., 1993; Lardelli et al., 1994; Uyttendaele et al., 1996). Agonistic Notch ligands belong to the Delta-like (Dll1, Dll4) and the Jagged family (Jag1, Jag2) (Figure 1), while Dll3 functions as a natural antagonist. Although Notch ligands are present in multiple tissues, their spatially restricted expression in defined cellular niches represents a recurrent mode of Notch signaling regulation. Notch1 and Notch2 are expressed by a wide range of cell types. Notch3 is primarily found in developing $\mathrm{T}$ cells, vascular smooth muscle and pericytes, and Notch4 in the endothelium. However, recent work reported new functional roles for Notch3 and Notch4 in other cells relevant to immune disorders such as synovial fibroblasts and macrophages for Notch3, and regulatory $\mathrm{T}$ cells for Notch4 (Harb et al., 2020; Lopez-Lopez et al., 2020; Wei et al., 2020). Notch receptors are single-pass transmembrane proteins with variations primarily in their extracellular ligand binding and intracellular signaling domains (Figure 1). Prior to ligandreceptor binding, the immature Notch receptor is cleaved in the Golgi complex by a furin-like convertase on its way to the cell surface. Furin-like convertases cleave Notch proteins at their S1 site to generate a non-covalently bound heterodimer. The joining ends of this heterodimer form a S2 region that is normally hidden within a "negative regulatory region," before it becomes vulnerable to cleavage by ADAM family metalloproteases. Ligand-receptor binding generates a physical force pulling on the Notch receptor, which exposes the S2 site to proteolytic cleavage by an ADAM metalloprotease (mostly ADAM10). S2 cleavage then generates a transmembrane intermediated that becomes sensitive to proteolysis by the $\gamma$-secretase complex at a third intramembrane site (S3) (De Strooper et al., 1999; Wolfe, 2020). $\gamma$-secretase releases the intracellular domain of Notch (ICN), allowing it to translocate into the nucleus to form a nuclear complex with the DNA-binding transcription factor RBP-Jк, also known as CBF1/Suppressor-of-hairless/Lag1 (CSL) (Tamura et al., 1995). The ICN/RBP-JK complex then enhances transcription of target genes through association with a Mastermind-like family coactivator (MAML1-3) and other proteins as part of a large transcriptional activation complex (Petcherski and Kimble, 2000; Wu et al., 2000; Nam et al., 2006; Wilson and Kovall, 2006). Importantly, transcriptional targets of Notch signaling are context-specific, and many reside in tissue-specific enhancers, enabling versatile functional outputs. In addition, non-canonical pathways of Notch signaling that bypass RBP-Jк and MAML have also been reported in immune cells, although their mechanisms and relative importance remain debated (Shin et al., 2006, 2014; Auderset et al., 2012; Dongre et al., 2014; Charbonnier et al., 2015; Harb et al., 2020).

The unique mechanisms of Notch activation have inspired genetic and pharmacological strategies of Notch inhibition (Figure 2 and Table 1). These loss-of-function strategies are essential to rigorously evaluate the effects of the Notch pathway in vivo, and some have translational potential. Conditional inactivation of Notch ligand and receptor genes in specific cell types requires knowledge of the expression pattern and relative importance of Notch ligand and receptor paralogs (Figure 2A). For example, combined Notch 1 and Notch 2 inactivation accounts for most effects of Notch signaling in mature $\mathrm{T}$ cells, although 


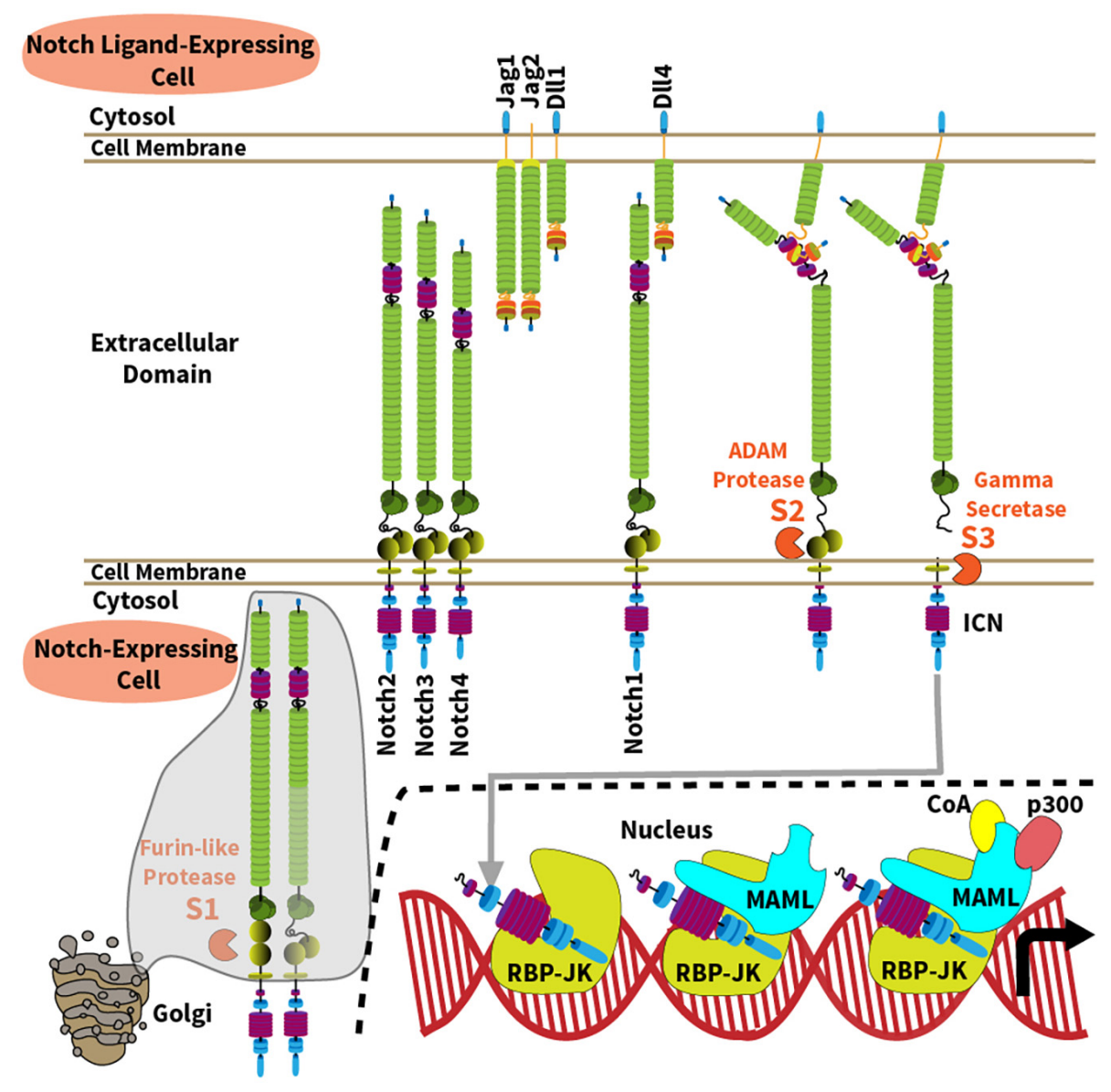

FIGURE 1 | Overview of the Notch signaling pathway. The Notch signaling pathway operates between four cell surface Notch receptors (Notch1-4) and four agonistic Notch ligands from the Jagged (Jag1, Jag2) and Delta-like families (D\|l1, DII4). Mechanisms of Notch activation and canonical signaling are depicted along the following steps: (1) A furin-like protease cleaves the Notch receptor into a transmembrane heterodimer during its transit to cell surface through the Golgi complex (S1 site); (2) Ligand-receptor binding generates a physical force onto the extracellular domain of the Notch receptor, allowing ADAM10-mediated proteolysis at the S2 site which is normally hidden within a "negative regulatory region" of the receptor; (3) ADAM10 generates a membrane-bound intermediate that becomes rapidly sensitive to intramembrane proteolysis by the $\gamma$-secretase complex (S3 site). As a result, intracellular Notch (ICN) is released into the cytoplasm and translocates into

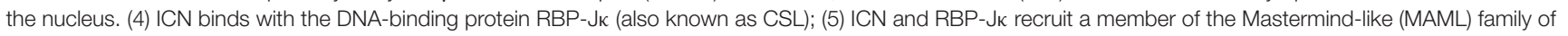
transcriptional coactivators via the N-terminal MAML alpha-helical domain; (6) In turn, MAML proteins recruit other transcriptional co-activators (CoA) and p300, respectively, to enhance transcription of Notch target genes.

Notch 1 loss is dominant in some contexts and Notch4 inactivation was also reported to affect Tregs (Auderset et al., 2012; Roderick et al., 2013; Tran et al., 2013; Backer et al., 2014; Charbonnier et al., 2015; Wei et al., 2020). In contrast, Notch1 inactivation alone blocks the effects of the pathway in early T cell development, while Notch2 loss is sufficient to inhibit Notch signaling in mature B cells and in dendritic cells (Radtke et al., 1999; Saito et al., 2003; Lewis et al., 2011). For Notch ligands, initial studies have focused on the role of their expression in professional antigen-presenting cells, such as conventional dendritic cells (Amsen et al., 2004). However, recent work highlighted critical immunological roles for Dll1 and Dll4 Notch ligands expressed by non-hematopoietic fibroblastic stromal cell niches in secondary lymphoid organs (Fasnacht et al., 2014; Chung et al., 2017; Perkey et al., 2020). Other genetic strategies that block canonical Notch signaling include inactivation of $R b p j$, encoding RBP-J $\kappa$, and conditional expression of dnMAML, a truncated N-terminal fragment of Mastermind-like1 (MAML1) fused to GFP that exerts potent dominant negative activity downstream of all Notch receptors (Tanigaki et al., 2002; Maillard et al., 2004). Although Notch-unrelated functions of MAML proteins have been reported, dnMAML only contains ca. 60 amino acids from the N-terminal MAML1 alpha-helix that bind ICN and RBP-JK, but not any other known partners. Thus, all effects reported so far for dnMAML have been related to its impact on Notch signaling. Finally, Notch loss-of-function phenotypes can also be induced by targeting other essential genes for Notch activation, e.g., Mib1 (encoding Mind bomb 1 , an ubiquitin ligase critical in Notch ligand-expressing cells); Pofut1 (encoding an O-Fucosyltransferase essential to modify 


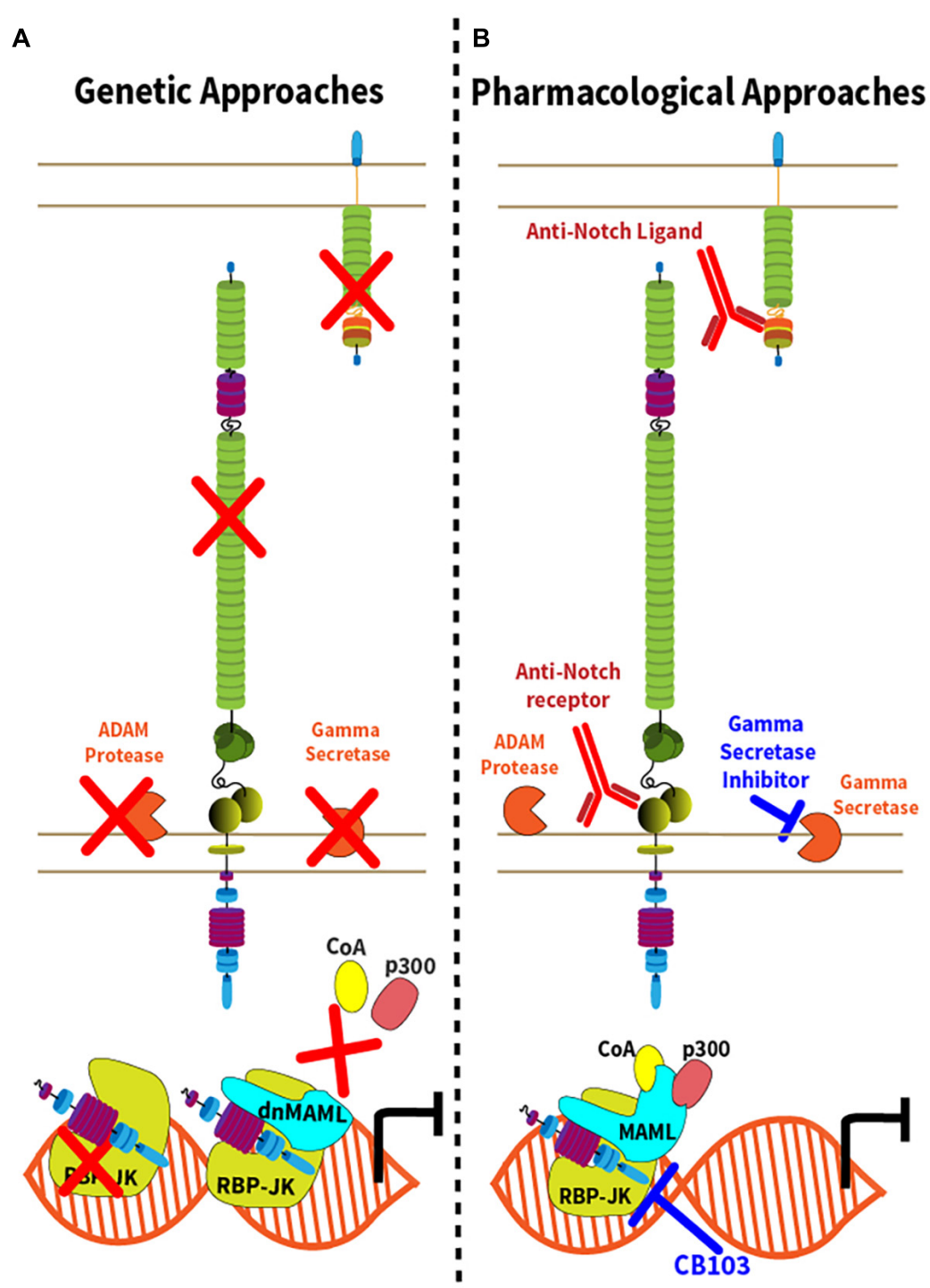

FIGURE 2 | Genetic and pharmacological approaches to Notch inhibition. (A) Genetic inactivation strategies leading to inhibition of the Notch signaling pathway are represented by red "X" with the exception of dnMAML, where the red "X" depicts the disruption of the Notch transcription activation complex due to expression of a truncated, dominant negative (dn) form of MAML1. In addition to conditional expression of dnMAML, commonly used approaches include conditional inactivation of Notch ligand genes, Notch receptor genes, Adam10, genes encoding components of the $\gamma$-secretase complex or Rbpj; (B) Strategies of pharmacological inhibition of Notch signaling either though the administration monoclonal antibodies targeting the Notch ligands or receptors, or small molecule inhibitors. $\gamma$-secretase inhibitors target components of the $\gamma$-secretase complex. CB-103 inhibits the Notch transcription complex.

mature Notch receptors); Adam10 (encoding the ADAM10 metalloprotease); and genes encoding subunits of the $\gamma$-secretase complex (such as Psen 1/2).

Complementing genetic approaches, pharmacological strategies with translational potential are depicted in Figure 2B. $\gamma$-secretase inhibitors (GSI) block the rate-limiting step of ligand-regulated proteolytic activation for all Notch receptors, thus achieving systemic pan-Notch inhibition (De Strooper et al., 1999; Wolfe, 2020). Monoclonal antibodies have been developed to inhibit individual Notch ligands or receptors, both in mice and in humans (Noguera-Troise et al., 2006; Ridgway et al., 2006;
Wu et al., 2010; Tran et al., 2013; Choy et al., 2017). By blocking specific Notch ligand and receptor paralogs, these antibodies have the potential to bypass some of the systemic effects of pan-Notch inhibition, thus increasing the therapeutic window. Finally, recent work reported the discovery of CB-103, a new orally active small molecule inhibitor of the Notch transcription activation complex, providing an alternative path to therapeutic Notch inhibition (Lehal et al., 2020). To facilitate understanding of currently available therapeutic interventions, we provide a list of key existing reagents together with their most advanced stage of development to date (Table 1). Importantly, findings in 
immune and inflammatory disorders remain preclinical, while our understanding of Notch targeting in cancer relies on both preclinical and clinical observations.

\section{TARGETING NOTCH SIGNALING IN CANCER AND IN TUMOR ANGIOGENESIS}

The oncogenic role of Notch signaling in cancer first sparked interest in therapeutic targeting of the Notch pathway, inspiring a first generation of preclinical and early clinical studies. Oncogenic activation of Notch signaling was originally described in 1991 in T cell acute lymphoblastic leukemia (T-ALL) based on a rare $t(7 ; 9)$ chromosomal translocation forcing expression of a constitutively active form of NOTCH1 (Ellisen et al., 1991). Later investigations showed that $>50 \%$ of T-ALL patients harbored NOTCH1 point mutations or other genetic events activating Notch signaling (Weng et al., 2004). While NOTCH1 mutations allowed for ligand-independent activation, they remained sensitive to GSI-mediated inhibition and prompted preclinical studies of Notch blockade as a targeted therapy in T-ALL (Weng et al., 2006; Cullion et al., 2009; Real et al., 2009; Tatarek et al., 2011; Samon et al., 2012; Sanchez-Martin et al., 2017). Other studies revealed oncogenic Notch activation in a wider range of cancer types, including breast cancer, adenoid cystic carcinoma and a variety of $B$ cell lymphoproliferative disorders, as reviewed in Aster et al. (2017). In some contexts, oncogenic Notch activation appeared to proceed via interaction of unmutated Notch ligands and receptors, suggesting that Notch pathway mutations may only identify a fraction of the Notch-sensitive tumors (Fabbri et al., 2017). In addition, other investigators identified a critical role of DLL4/NOTCH1 interactions as well as a crosstalk of the Notch and VEGF pathways in tumor angiogenesis (Noguera-Troise et al., 2006; Ridgway et al., 2006). These effects of Notch in the tumor microenvironment formed the initial rationale for several drug development programs and motivated testing of anti-DLL4 antibodies in cancer patients. Importantly, most cancer-related indications of therapeutic Notch inhibition focused on continuous and longlasting inhibition of the pathway as a desirable outcome, which also contributed to reported side effects.

\section{Development of $\gamma$-Secretase Inhibitors (GSIs)}

The first drugs used to target Notch in the clinic originated from groundbreaking work designed to target the $\gamma$-secretase complex in Alzheimer's disease. In Alzheimer's, $\gamma$-secretase plays a critical role in the cleavage of the amyloid precursor protein, subsequently forming aggregates of amyloid-beta peptides in the brain as a major contributor to disease progression (Haass and Selkoe, 1993). GSIs target Presenilin components of the $\gamma$-secretase complex, locking it in a closed conformation and inhibiting the deposition of amyloid-beta peptides. This discovery inspired clinical trials of GSIs in Alzheimer's disease. Importantly, originally designed GSIs also inhibited proteolytic activation of all transmembrane-bound Notch receptors, effectively silencing all Notch activity (De Strooper et al., 1999; Wolfe, 2020). Although GSIs have not proven successful so far in Alzheimer's disease, they opened the door to preclinical and early clinical studies of Notch inhibition in cancer (Doody et al., 2013).

\section{GSIs in Human Cancer Clinical Trials}

The first Phase 1 clinical trial targeting Notch evaluated the GSI MK-0752 in relapsed/refractory T-ALL (Deangelo et al., 2006). MK-0752 is a broad-spectrum GSI originally designed to treat Alzheimer's disease, but repurposed for the treatment of T-ALL. MK-0752 demonstrated some efficacy in inhibiting T-ALL expansion and showed disease regression in a small number of patients (Deangelo et al., 2006). However, many patients suffered significant diarrhea in a dose-dependent manner, which may have limited treatment to suboptimal or intermittent dosing, thus decreasing drug efficacy. Intestinal side effects of GSIs likely resulted from on-target toxicity from pan-Notch inhibition in gut (van Es et al., 2005; Deangelo et al., 2006; VanDussen et al., 2012). Indeed, preclinical studies in mice using GSIs and/or genetic approaches showed that Notch is critical for the homeostasis of intestinal stem and progenitor cells. Rbpj inactivation in Villin-Cre ${ }^{+}$intestinal cells or the use of GSIs induced the differentiation of intestinal crypt cells into postmitotic goblet cells, leading to severe diarrhea (van Es et al., 2005). Paneth cells, located at the basis of intestinal crypts, appeared to function as a niche for intestinal stem cells (Sato et al., 2011). This damage was most pronounced when both Notch1 and Notch2 were inhibited (Riccio et al., 2008; Wu et al., 2010). In studies involving irradiation, even more severe epithelial intestinal damage was documented after GSI treatment, suggesting a role for Notch in intestinal regeneration (Tran et al., 2013). Diarrhea is not exclusive to MK-0752. Other firstgeneration GSIs such as AL-101, Crenigacestat, and Nirogacestat also exhibited similar gastrointestinal toxicities, along with a few other complications such as fatigue, anemia, thrombocytopenia, and hypophosphatemia that could also have been related to the concomitant use of chemotherapy (Messersmith et al., 2015; Cook et al., 2018; El-Khoueiry et al., 2018; Massard et al., 2018). Nonetheless, the use of first-generation GSIs has not been completely discontinued in clinical trials. In some ongoing trials, first-generation GSIs are being evaluated for their use in combination therapies with already approved anti-cancer treatment modalities. These studies deploy GSIs at tolerable doses or with decreased frequency, while working synergistically with other treatments to suppress tumor growth. In preclinical data, intermittent GSI dosing indeed appeared to open a therapeutic window (Cullion et al., 2009; Tatarek et al., 2011). Another approach relies on the combination of GSIs and corticosteroids, which appear to suppress the gastrointestinal side effects of pan-Notch inhibition (Real et al., 2009; Samon et al., 2012). Finally, selection of GSI-resistant tumor cells represents another barrier to therapeutic Notch inhibition (Palomero et al., 2007; Knoechel et al., 2014; Aster et al., 2017). Altogether, firstgeneration GSIs have not been tolerated well enough to show deep efficacy as stand-alone drugs. Several strategies are being 
TABLE 1 | List of key Notch inhibitors tested preclinically or clinically so far, subcategorized by name/alias, their target and cross-reactivity to humans (h), mice (m), or primates (p).

\begin{tabular}{|c|c|c|c|c|}
\hline Drug/Alias name & Target & Latest phase, indication & Key references & Clinical Trials Identifier \\
\hline DAPT & $\gamma$-secretase & Preclinical: Tumor & Morohashi et al., 2006 & \\
\hline MRK-560 & $\begin{array}{l}\gamma \text {-secretase- } \\
\text { Presenilin1 }\end{array}$ & Preclinical - T-ALL & $\begin{array}{l}\text { Best et al., 2007; Habets et al., } \\
2019\end{array}$ & \\
\hline MRK-003 & $\gamma$-secretase & Preclinical - T-ALL, solid tumor & $\begin{array}{l}\text { Ramakrishnan et al., 2012; Tanaka } \\
\text { et al., } 2015\end{array}$ & \\
\hline LY900009 & $\gamma$-secretase & Phase I: Tumor & Pant et al., 2016 & NCT01158404 \\
\hline AL 101 (BMS-906024) & $\gamma$-secretase & $\begin{array}{l}\text { Phase II: Tumor; Preclinical: } \\
\text { Insulin resistance }\end{array}$ & $\begin{array}{l}\text { Ferrarotto et al., 2019; Sparling } \\
\text { et al., } 2020\end{array}$ & $\begin{array}{l}\text { NCT04461600 NCT03691207 } \\
\text { NCT01292655 NCT01363817 } \\
\text { NCT01653470 }\end{array}$ \\
\hline Crenigacestat (LY3039478) & $\gamma$-secretase & Phase II: Tumor & Mancarella et al., 2020 & $\begin{array}{l}\text { NCT02836600 NCT02906618 } \\
\text { NCT02917733 NCT02659865 } \\
\text { NCT02518113 NCT02784795 } \\
\text { NCT01695005 NCT03502577 }\end{array}$ \\
\hline MK0752 & $\gamma$-secretase & Phase II: Tumor & Whitehead et al., 2012 & $\begin{array}{l}\text { NCT00756717 NCT00803894 } \\
\text { NCT00572182 NCT00645333 } \\
\text { NCT01098344 NCT01295632 } \\
\text { NCT01243762 NCT00106145 } \\
\text { NCT00100152 }\end{array}$ \\
\hline Nirogacestat (PF-03084014) & $\gamma$-secretase & Phase III: Tumor & Kummar et al., 2015 & $\begin{array}{l}\text { NCT02299635 NCT02462707 } \\
\text { NCT02338531 NCT01981551 } \\
\text { NCT01876251 NCT02955446 } \\
\text { NCT02109445 NCT00878189 } \\
\text { NCT04195399 NCT03785964 }\end{array}$ \\
\hline RO4929097 (RG473) & $\gamma$-secretase & Phase II: Tumor & $\begin{array}{l}\text { Luistro et al., 2009; Sahebjam } \\
\text { et al., 2013; Lee et al., } 2015\end{array}$ & $\begin{array}{l}\text { NCT01238133 NCT01175343 } \\
\text { NCT01154452 NCT01198535 } \\
\text { NCT01232829 NCT01141569 } \\
\text { NCT01122901 NCT01116687 } \\
\text { NCT01131234 NCT01120275 } \\
\text { NCT01217411 NCT01193881 } \\
\text { NCT01193868 NCT01269411 } \\
\text { NCT01088763 NCT01251172 } \\
\text { NCT01216787 NCT01145456 } \\
\text { NCT01158274 NCT01071564 } \\
\text { NCT01270438 NCT01151449 } \\
\text { NCT01196416 NCT01096355 } \\
\text { NCT01189240 NCT01192763 } \\
\text { NCT01200810 NCT01198184 } \\
\text { NCT01119599 NCT01149356 } \\
\text { NCT01070927 NCT01236586 } \\
\text { NCT01208441 NCT01218620 } \\
\text { NCT00532090 }\end{array}$ \\
\hline
\end{tabular}

\begin{tabular}{|c|c|c|c|c|}
\hline CT16 & hNotch 2/3, hEGFR & Preclinical: Tumor & Hu et al., 2017 & \\
\hline PTG12 & hEGFR/hNotch 2/3 & Preclinical: Tumor & Fu et al., 2019 & \\
\hline Anti-NRR1 & $\mathrm{h} / \mathrm{mNotch} 1$ & $\begin{array}{l}\text { Preclinical: Tumor, GVHD, graft } \\
\text { rejection }\end{array}$ & $\begin{array}{l}\text { Wu et al., 2010; Tran et al., 2013; } \\
\text { Magee et al., } 2019\end{array}$ & \\
\hline Anti-NRR2 & $\mathrm{h} / \mathrm{mNotch} 2$ & Preclinical: Tumor, GVHD & Wu et al., 2010; Tran et al., 2013 & \\
\hline Brontictuzumab (OMP-52M51) & hNotch 1 & Phase I: Tumor & Ferrarotto et al., 2018 & $\begin{array}{l}\text { NCT01778439 NCT01703572 } \\
\text { NCT02662608 NCT03031691 }\end{array}$ \\
\hline Tarextumab (OMP-59R5) & hNotch 2/3 & Phase II: Tumor & Hu et al., 2019 & $\begin{array}{l}\text { NCT01277146 NCT01647828 } \\
\text { NCT01859741 }\end{array}$ \\
\hline $15 \mathrm{D} 11$ & hJag 1 & Preclinical: Tumor & Zheng et al., 2017 & \\
\hline Anti-Jag1/2 & hJag1/2 & Preclinical: Airway & Yan et al., 2010 & \\
\hline Anti-D\|l1 & $\mathrm{h} / \mathrm{mD} \| 1$ & $\begin{array}{l}\text { Preclinical: GVHD, graft } \\
\text { rejection }\end{array}$ & Liang et al., 2006; Tran et al., 2013 & \\
\hline YW152F & $\mathrm{h} / \mathrm{mD} \| 4$ & $\begin{array}{l}\text { Preclinical: Tumors, GVHD, } \\
\text { graft rejection }\end{array}$ & $\begin{array}{l}\text { Liang et al., 2006; Ridgway et al., } \\
\text { 2006; Tran et al., 2013; Wood } \\
\text { et al., } 2015\end{array}$ & \\
\hline MMGZ01 & $\mathrm{hD} \| 4$ & Preclinical: Tumor & Jia et al., 2016; Xu et al., 2016 & \\
\hline
\end{tabular}


TABLE 1 | Continued

\begin{tabular}{|c|c|c|c|c|}
\hline Drug/Alias name & Target & Latest phase, indication & Key references & Clinical Trials Identifier \\
\hline mABL001 & mD\|4, mVEGF & Preclinical: Tumor & Kim et al., 2020 & \\
\hline HMD4-2 & $\mathrm{h} / \mathrm{mD} \| 4$ & Preclinical: Tumor & Yamanda et al., 2009 & \\
\hline Demcizumab (OMP-21M18) & $\mathrm{hD} \| 4$ & Phase I: Tumor & $\begin{array}{l}\text { Smith et al., 2014; McKeage et al., } \\
2018\end{array}$ & $\begin{array}{l}\text { NCT00744562 NCT01189942 } \\
\text { NCT01189968 NCT01189929 } \\
\text { NCT02722954 NCT01952249 }\end{array}$ \\
\hline Enoticumab (REGN421) & $\mathrm{hD} \| 4$ & Phase I: Tumor & Chiorean et al., 2015 & NCT00871559 \\
\hline MEDI0639 & $\mathrm{hD \|} 4$ & Phase I: Tumor & $\begin{array}{l}\text { Jenkins et al., 2012; Falchook } \\
\text { et al., } 2015\end{array}$ & NCT01577745 \\
\hline Navicixizumab (OMP-305B83) & hD\|l, hVEGF & Phase I: Tumor & $\begin{array}{l}\text { Jimeno et al., 2019; Perez-Fidalgo } \\
\text { et al., } 2020\end{array}$ & $\begin{array}{l}\text { NCT03035253 NCT02298387 } \\
\text { NCT03030287 }\end{array}$ \\
\hline ABT-165 & hD\|4, hVEGF & Phase II: Tumor & $\begin{array}{l}\text { Li et al., 2018; Wainberg et al., } \\
2018\end{array}$ & NCT03368859 NCT01946074 \\
\hline NOV1501 (ABL001; HD105) & $\mathrm{h} / \mathrm{pD} \| 4, \mathrm{~h} / \mathrm{pVEGF}$ & Phase II: Tumor & $\begin{array}{l}\text { Choi et al., 2016; Lee et al., 2016; } \\
\text { Sosa Iglesias et al., 2018; Kim } \\
\text { et al., 2020; Yeom et al., } 2021\end{array}$ & NCT03292783 NCT04492033 \\
\hline IMR-1 & hRBPJ/ICN1/MAML & Preclinical: Tumor & Lafkas et al., 2015 & \\
\hline RIN1 & hRPBJ & Preclinical: Tumor & Hurtado et al., 2019 & \\
\hline SAHM1 & $\mathrm{h} / \mathrm{mlCN} 1 / \mathrm{RBPJ}$ & Preclinical: Tumor, Airway & $\begin{array}{l}\text { Moellering et al., 2009; KleinJan } \\
\text { et al., 2018; Takam Kamga et al., } \\
2019\end{array}$ & \\
\hline CB-103 & hRBPJ/MAML & Phase $1 /$ lla & Lehal et al., 2020 & NCT04714619 NCT03422679 \\
\hline
\end{tabular}

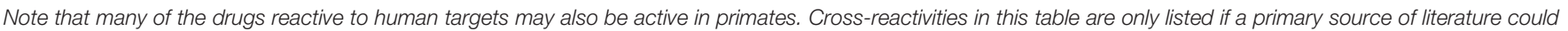
be found. Clinical trials using these drugs are listed with their unique identifier in clinicaltrials.gov.

tested or considered to improve the therapeutic index of these drugs: (1) Modified administration schedules, for example with intermittent administration; (2) Combination therapy with other drugs to enhance efficacy or mitigate toxicity; (3) Development of new generations of drugs that show enhanced specificity for Notch signaling in cancer (Habets et al., 2019; Yang et al., 2020). Importantly, these changes have to be paired with a better identification of patients with documented Notch tumor activation, as opposed to unselected cancer patients.

\section{Monoclonal Antibodies Blocking Notch Receptors and Ligands}

To bypass the toxicities of systemic pan-Notch inhibition, humanized monoclonal antibodies have been developed against individual Notch1, Notch2, and Notch3 paralogs. In mice, Notch1 inhibition alone was much better tolerated than combined Notch1/2 inhibition, consistent with the redundant role of Notch1 and Notch2 in intestinal stem cell homeostasis (Riccio et al., 2008; Wu et al., 2010). In preclinical models, Notch1 or Notch3 inhibition alone had promising activity in specific models of T-ALL and breast cancer (Wu et al., 2010; Choy et al., 2017). To date, blocking antibodies against Notch1 and Notch2/3 have been clinically evaluated for the treatment of tumors (Smith et al., 2014; Yen et al., 2015; Ferrarotto et al., 2018). Reports on anti-Notch1 blockade indicated some activity in patients with hematological and solid tumors (Casulo et al., 2016; Ferrarotto et al., 2018). However, despite indications in mice, gut toxicity was still a problem in phase 1 trials (Casulo et al., 2016; Ferrarotto et al., 2018). Initial data of anti-Notch2/3 blocking antibodies were promising in solid tumors (Yen et al., 2015).
However, a randomized phase 2 trial showed that benefits were contributed primarily by chemotherapy and not anti-Notch $2 / 3$ (Pietanza et al., 2015; Hu et al., 2019). Altogether, these findings represent progress in limiting the systemic toxicity of Notch inhibition, although clinical activity was not impressive so far, at least when patients were not selected upfront for having Notchdependent tumors.

Dll4-regulated tumor angiogenesis has inspired the development of anti-DLL4 antibodies, as well as their study in both preclinical and early clinical models. Solid tumors induce a network of blood vessels to provide continuous oxygen and nutrient supplies that sustain their growth (Folkman, 1971). To date, vascular endothelial growth factor (VEGF) remains the primary clinical target used to suppress tumor angiogenesis (Keck et al., 1989; Leung et al., 1989). The role of Notch in angiogenesis has been extensively documented as part of a crosstalk between DLL4/NOTCH1 and VEGF (Noguera-Troise et al., 2006; Ridgway et al., 2006). Preclinical work showed that the effects of anti-DLL4 and anti-VEGF do not overlap, with a potential for anti-DLL4 to overcome resistance to anti-VEGF therapy (Ridgway et al., 2006). Mechanistically, DLL4 inhibition increased angiogenic sprouting, but led to non-productive blood vessel formation and diminished tumor growth (Noguera-Troise et al., 2006). In a human phase I clinical trial of DLL4 blockade, intestinal side effects were not observed, but cardiovascular events associated with prolonged DLL4 inhibition were reported, including hypertension, pulmonary hypertension and congestive heart failure (Smith et al., 2014; Chiorean et al., 2015; Falchook et al., 2015; McKeage et al., 2018). In addition, chronic DLL4 blockade has been reported to cause vascular anomalies in rats and monkeys (Yan et al., 2010). Thus, 
while anti-DLL4 may bypass the side effects previously observed with GSI or combined anti-NOTCH1/2 antibodies, chronic DLL4 inhibition as required for optimal anti-cancer activity remains problematic.

\section{New Pharmacological Approaches to Target Notch Signaling in Cancer}

New generation GSIs are being developed to target specific components of the $\gamma$-secretase complex (Churcher et al., 2006; Best et al., 2007; Habets et al., 2019). MRK-560 has gained traction as a treatment for T-ALL because studies have shown MRK-560 to be more tolerable, with reduced gastrointestinal side effects in preclinical animal models (Habets et al., 2019). Different $\gamma$-secretase complexes contain variable proportions of the two Presenilins, PSEN1 and PSEN2 (Kimberly et al., 2003). MRK-560 has a ca. 100-fold selectivity for PSEN1 over PSEN2 (Borgegard et al., 2012). In contrast to dominant expression of PSEN1 in T-ALL, PSEN1 and PSEN2 both expressed in mouse and human intestine (Habets et al., 2019). Indeed, pharmacological PSEN1 inhibition by MRK-560 attenuated T-ALL growth in mice (Habets et al., 2019). As a separate approach, Lehal et al. (2020) recently reported the development of CB-103, a firstin-class inhibitor of the Notch transcription complex. CB-103 showed promising preclinical activity in the treatment of T-ALL and other Notch-dependent tumors, including GSI-resistant cell lines, without inducing significant intestinal toxicity for reasons that remain to be fully clarified. This promising activity profile has led to ongoing clinical trials of CB-103 in cancer. Thus, new compounds are being developed to target Notch signaling in cancer, and it will be interesting to evaluate if they also have therapeutic potential in non-malignant conditions such as Notch-driven immune disorders.

\section{TARGETING NOTCH SIGNALING IN INFLAMMATORY AND IMMUNE DISORDERS}

In the immune system, Notch signaling was first identified for its essential role in early T cell development (Pui et al., 1999; Radtke et al., 1999). Dll4 inactivation in cortical thymic epithelial cells or Notch 1 loss in lymphoid progenitors blocks T cell development in the thymus (Radtke et al., 1999; Hozumi et al., 2008; Koch et al., 2008). Other developmental functions of Notch signaling regulate the emergence of definitive hematopoietic stem cells in the fetus as well as various aspects of B cell, innate lymphoid cell and dendritic cell development (Tanigaki et al., 2002; Saito et al., 2003; Lewis et al., 2011; Satpathy et al., 2013; Yang et al., 2013). Beyond development, mature immune cells express Notch receptors (most commonly a combination of Notch1 and/or Notch2), and they can interact with Notch ligands in their microenvironment (e.g., in secondary lymphoid organs or in tissues). On this basis, Notch signaling exerts essential functions during specific immune responses, including in many contexts with relevance to human health and disease. These discoveries have identified a new set of Notch-related therapeutic opportunities.
From a translational perspective, the principles of targeting Notch signaling in immune and inflammatory disorders build on different rules than in cancer-related indications. In cancer, prolonged Notch inhibition is desirable, which has been linked to the occurrence of problematic on-target side effects. In addition, cancer cells can be selected for acquired resistance to Notch inhibition through epigenetic and other mechanisms. In the immune system, selection of clones resistant to Notch inhibition is not an issue, and Notch blockade can be applied transiently at sensitive stages of immune cell differentiation and function. This strategy would have the advantage to preserve Notchmediated functions in lymphoid development and beneficial immune responses that develop outside of the transient windows of Notch inhibition. We will now review emerging evidence about essential pathogenic functions of Notch signaling in immune and inflammatory disorders that could become the target of therapeutic interventions.

\section{Experimental Autoimmune Encephalomyelitis and Multiple Sclerosis}

Minter and collaborators first described a pathogenic role of Notch signaling in T cells mediating Experimental Autoimmune Encephalomyelitis (EAE) in mice, a model that shares many features with human Multiple Sclerosis (MS) (Minter et al., 2005). Using GSIs in vivo and ex vivo, the authors reported attenuated EAE severity and a decreased propensity of $\mathrm{CD} 4^{+} \mathrm{T}$ cells to differentiate into Th1 cells expressing Tbx21 (encoding the master transcription factor T-bet). These findings were consistent with critical effects of Notch signaling in $\mathrm{CD} 4^{+} \mathrm{T}$ cells, which play a key role in EAE pathogenesis both through Th1 and Th17 differentiation. The T cell-intrinsic pathogenic functions of Notch during EAE were subsequently confirmed via $\mathrm{T}$ cell-specific Rbpj inactivation or expression of the panNotch inhibitor DNMAML, which provided high protection from EAE induced by polyclonal $\mathrm{T}$ cells or by myelin-specific 2D2 T cell receptor transgenic T cells (Sandy et al., 2013b). The impact of RBP-Jk and DNMAML was consistent with a dominant role of canonical RBP-Jk/MAML-dependent signaling in encephalitogenic $\mathrm{T}$ cells during EAE. In this study, Notch inhibition did not impair Th1 and Th17 differentiation in the periphery, but profoundly inhibited the accumulation of $\mathrm{T}$ cells in the brain and spinal cord. Other investigators reported protection from EAE upon systemic inhibition of Dll4 Notch ligands, with an impact on $\mathrm{T}$ cell infiltration in the central nervous system, Treg expansion and Th1/Th17 differentiation, respectively (Bassil et al., 2011; Reynolds et al., 2011; Eixarch et al., 2013). Finally, Notch may also impact Th9 differentiation and myelin repair mechanisms (Jurynczyk et al., 2005; Elyaman et al., 2012).

Altogether, Notch signaling is emerging as a central regulator of EAE pathogenesis, with $\mathrm{T}$ cell-intrinsic functions playing a major role. Additional investigations combining genetic and pharmacological approaches are needed to carefully dissect the impact of Notch signaling in T cells vs. other cell types involved in EAE progression. From a translational perspective, it will be essential to evaluate the role of Dll4 as opposed to other Notch ligands; map the cellular source of Notch ligands as 
well as their spatial and temporal interactions with T cells; and define the critical time windows during which systemic Notch inhibition induces maximum benefits. For example, it would be interesting to define if and when transient systemic Notch ligand inhibition can abort disease flares by itself or in combination with other interventions.

\section{Graft-Versus-Host Disease After Allogeneic Hematopoietic Cell Transplantation}

Allogeneic bone marrow or hematopoietic cell transplantation (allo-HCT) is a potentially life-saving therapeutic modality for patients with benign and malignant hematological disorders, including leukemias and lymphomas. However, acute and chronic graft-versus-host disease (GVHD) remain major immune complications of the procedure that limit its success and curtail its widespread use. GVHD is triggered by donor-derived $\mathrm{T}$ cells in the hematopoietic graft that recognize foreign tissue antigens in the recipient, leading to target organ damage. Unmet clinical needs include the occurrence of GVHD in a high fraction of patients despite universal use of prophylactic immunosuppression; severe acute GVHD, especially when resistant to corticosteroids; extensive forms of chronic GVHD, which induce serious life-long morbidity; and the need to control GVHD without eliminating the beneficial graft-versus-tumor effects of allo-HCT in cancer patients.

In the past 10 years, Notch inhibition in donor $\mathrm{T}$ cells has emerged as an attractive new strategy to control GVHD without inducing global immunosuppression. Protective effects of Notch inhibition were observed in multiple mouse allo-HCT models of acute and chronic GVHD, across major and minor histocompatibility antigen mismatches, after conditioning regimens of variable types and intensity, and also in a model of aplastic anemia mediated by alloreactive $\mathrm{T}$ cells (Zhang et al., 2011; Mochizuki et al., 2013; Roderick et al., 2013; Sandy et al., 2013a; Tran et al., 2013). Inhibition of canonical Notch signaling accounted for all major effects of Notch blockade in $\mathrm{T}$ cells (Zhang et al., 2011; Tran et al., 2013; Charbonnier et al., 2015). Combined Notch1 and Notch2 blockade in $\mathrm{T}$ cells was necessary to achieve maximum effects of Notch inhibition, but with a major role for Notch1 (Tran et al., 2013; Radojcic et al., 2018). In one report, protective effects were reported upon Notch1/2 inactivation only in regulatory $\mathrm{T}$ cells (Tregs) (Charbonnier et al., 2015). In terms of Notch ligands, Dll1 and Dll4 in the host accounted for all the effects of Notch signaling in GVHD, with a dominant role for Dll4 (Mochizuki et al., 2013; Tran et al., 2013; Chung et al., 2019; Perkey et al., 2020). Mechanistically, Notch inhibition blunted the production of multiple inflammatory cytokines in alloreactive T cells, including IFN $\gamma, \mathrm{TNF} \alpha$ and IL-17, while leading to increased expansion of preexisting Tregs, enhanced Treg function and decreased accumulation of $\mathrm{T}$ cells in the gut (Zhang et al., 2011; Sandy et al., 2013a; Tran et al., 2013; Charbonnier et al., 2015). Notch inhibition rapidly established a unique transcriptional signature in alloreactive
T cells within days after transplantation, although all direct transcriptional targets remain to be identified systematically through genome-wide approaches (Chung et al., 2019). Importantly, and unlike conventional immunosuppression, Notch blockade did not inhibit the activation and expansion of alloreactive $\mathrm{T}$ cells in secondary lymphoid organs, and it preserved high levels of cytotoxicity and anti-cancer activity (Zhang et al., 2011; Sandy et al., 2013a; Tran et al., 2013). Thus, Notch inhibition in T cells did not cause global immunosuppression, but instead induced a beneficial pattern of immunomodulation after allo-HCT.

From a translational perspective, systemic pan-Notch inhibition with GSIs showed on-target activity in alloreactive $\mathrm{T}$ cells similar to that of genetic interventions, but also side effects in the gut that were poorly tolerated (Tran et al., 2013). Although not unexpected given the known functions of Notch signaling in intestinal epithelial cells during homeostasis, this on-target toxicity was enhanced after transplantation, likely due to a role of Notch signaling in intestinal regeneration after injury from conditioning irradiation (van Es et al., 2005; Riccio et al., 2008; Tran et al., 2013). Thus, GSIs are not promising in this context. Bypassing these limitations, targeted antibody-mediated inhibition of the Notch ligands Dll1 and Dll4 were efficient at controlling GVHD and well tolerated (Tran et al., 2013; Chung et al., 2017). Importantly, early Dll1/4 inhibition during the first 2 days after allo-HCT proved essential to induce GVHD protection, suggesting that critical pathogenic Notch signals are delivered to incoming T cells very early after transplantation (Chung et al., 2017). Conversely, short-term Notch inhibition even with a single dose of anti-Dll1/4 antibodies was sufficient to confer long-term protection from GVHD. During early days after allo-HCT, T cells were found to interact with Dll1/4 ligands expressed by specialized niches of non-hematopoietic fibroblastic reticular cells lineage traced with a Ccl19-Cre transgene in secondary lymphoid organs (Chung et al., 2017; Perkey et al., 2020). The dominant role of non-hematopoietic cells as a source of Notch ligands in this context came as a surprise, as dendritic cells as well as other professional antigen-presenting cells had been considered previously as the likely source of ligands. Nevertheless, this pattern of Notch ligand-receptor interactions in secondary lymphoid organs is reminiscent of regulation in the thymus, where Notch ligands in non-hematopoietic thymic epithelial cells interact with Notch receptors in $\mathrm{T}$ cell progenitors.

Altogether, these findings support continued translational investigations of Notch ligand inhibition as a new strategy to prevent GVHD. The long-term benefits of short-term Notch inhibition at the time of transplant are particularly relevant, as they avoid the consequences of prolonged Notch blockade, including inhibition of Dll4/Notch1-driven T cell development in the thymus and other potential negative consequences. Importantly, emerging data indicate that the central role of Notch signaling in GVHD is conserved from mice to non-human primates. Indeed, short-term DLL4 blockade at the time of transplant induced significant protection from GVHD in a Rhesus macaque model similar to human transplantation, even 
with a single dose of antibodies (Tkachev et al., 2018). Thus, Notch ligand blockade could be considered to prevent GVHD in human allo-HCT.

\section{Rejection After Allogeneic Solid Organ Transplantation}

Acute and chronic immune-mediated rejection limit the success of solid organ transplantation in patients, such as heart, lung, liver or kidney transplant recipients. In addition, the risk of rejection mandates long-term administration of global immunosuppressive drugs, such as calcineurin inhibitors, which carry significant side effects including vascular and renal toxicity, a propensity to opportunistic infections and posttransplant lymphoproliferative disorders. Thus, new strategies to prevent rejection are needed, ideally by inducing tolerance to transplanted allogeneic organs.

Early work using ex vivo and in vivo exposure of $\mathrm{T}$ cells to overexpressed Notch ligands suggested a role for Notch signaling in tolerance induction (Vigouroux et al., 2003; Wong et al., 2003; Yvon et al., 2003). However, artificial features of these experimental systems did not allow for definitive conclusions about the role of Notch signaling, and instead multiple convergent reports have now identified Notch as a major pro-inflammatory pathway driving organ rejection in vivo. Riella et al. (2011) first reported a role for the Notch pathway in transplant rejection by targeting the Notch ligand Dll1 with monoclonal antibodies in a mouse model of heart transplantation. Together with B7-CD28 blockade, anti-Dll1 antibodies induced significant, although relatively modest, protection from heart rejection, which was associated with STAT6-dependent Th2 polarization. Conversely, Jagged2mediated agonism accelerated rejection through an IL6dependent pathway (Riella et al., 2013). Although these studies captured consistent pro-rejection effects of Notch signaling, they only investigated the impact of isolated Notch ligands. Using expression of the pan-Notch inhibitor DNMAML in T cells, Wong et al. (2003) reported delayed rejection of mouse allogeneic heart transplants, which was most pronounced upon concomitant CD8 depletion (Wood et al., 2015). Protection was associated with decreased $\mathrm{T}$ cell infiltration and an increased proportion of Tregs in the graft. Furthermore, a short course of antibody-mediated Dll1/4 blockade over 10 days led to even better protection than pan-Notch inhibition in T cells, as well as to decreased alloantibody production and complement deposition in the graft (two features of chronic rejection). Thus, systemic Dll1/4 blockade may exert protective effects through its impact on both alloreactive T cells and other pathogenic cell types (e.g., B cells and plasma cells). Recently, Riella's group reported major protective effects of anti-Notch1 neutralizing antibodies when administered during 10 days after transplantation of MHCmismatched heart allografts (Magee et al., 2019). Protection was associated with evidence of increased Treg expansion and function. Prolonged graft survival was particularly impressive when anti-Notch1 antibodies were combined with CTLA4Ig, suggesting that a tolerance-like state can be achieved in these conditions.
Together, this growing body of work identifies strategies of Notch inhibition with translational potential in the prevention of organ rejection. Selective inhibition of individual Notch ligands or receptors is attractive to prevent the systemic side effects of pan-Notch inhibition, especially when applied transiently. As seen in GVHD, short-term inhibition in the peri-transplant period exerts long-term protective effects, which limits the potential consequence of prolonged Notch ligand or receptor inhibition. More work needs to identify all target cell types, and the most promising treatment combinations, although the joint effects of Notch blockade and CTLA4-Ig are particularly interesting.

\section{Asthma and Allergic Airway Inflammation}

Asthma is characterized by bronchial hyperreactivity and airway infiltration by $\mathrm{T}$ lymphocytes, innate lymphoid cells, macrophages, neutrophils, mast cells and eosinophils, with important inflammatory roles for both innate and adaptive immune cells. $\mathrm{CD}^{+} \mathrm{T}$ cell differentiation to a $\mathrm{T}$ helper 2 (Th2) phenotype under the control of the master transcription factor GATA3 is central to disease pathogenesis via secretion of Th2 cytokines (e.g., IL-4, IL-5, IL-13), although Th17 differentiation also takes place. Ex vivo work using coculture with antigen-presenting cells first identified the potential for Jagged ligands to drive $\mathrm{CD} 4^{+} \mathrm{Th} 2$ polarization (Amsen et al., 2004). In several mouse models of Th2 differentiation, Notch was reported to directly regulate Gata3 and Il4 transcription, the latter through ICN binding at the Il4 CNS2 enhancer element (Tu et al., 2005; Tanaka et al., 2006; Amsen et al., 2007; Fang et al., 2007). Other groups proposed that Notch can sustain and amplify, rather than initiate, multiple types of $\mathrm{T}$ helper responses (Bailis et al., 2013; Laky et al., 2015). Collectively, these studies inspired researchers to evaluate pharmacological strategies of Notch inhibition in models of asthma and allergic airway inflammation. Administration of GSIs blunted disease pathogenesis and Th2 differentiation in a mouse asthma model induced by ovalbumin sensitization (Kang et al., 2009). Other investigators reported an impact of GSIs on Th17 differentiation (Zhang et al., 2015). In a house dust mite model, eosinophil infiltration, Th2 differentiation and bronchial hyperreactivity were blunted by topical intratracheal administration of the stapled peptide SAHM1, which blocks Notch-mediated transcriptional activation (Moellering et al., 2009; KleinJan et al., 2018). Antibody-mediated blockade of Jagged1 and Dll4 ligands had opposite effects in an ovalbumin-driven model, with Jagged 1 blockade ameliorating the disease and Dll4 inhibition worsening it, possibly via an effect on Tregs (Huang et al., 2017). Systemic Dll4 blockade also enhanced bronchial hyperresponsiveness and inflammation in mouse models of airway hyperreactivity following Respiratory Syncytial Virus infection (Schaller et al., 2007). Thus, the impact of individual Notch ligands and receptors in asthma and related conditions is profound but complex.

Recent work is expanding our understanding of Notch signaling in asthma, revealing new mechanisms and unexpected players. Tindemans et al. (2020) used a house dust mite mouse model of allergic airway inflammation to document genetically a major pathogenic role of Notch1 and Notch 2 in T cells. 
Interestingly, transgenic Gata3 expression in Notch1/2-deficient or $R b p j$-deficient $\mathrm{T}$ cells only had a limited impact on their phenotype, suggesting Gata3-independent effects of canonical Notch signals. Instead, Notch was found to promote lymph node egress and trafficking of $\mathrm{CD} 4^{+} \mathrm{T}$ cells into the lung, possibly via a KLF2/S1PR1 axis. Recently, Chatila's group described a Jagged1Notch 4 signaling axis at the core of asthma pathogenesis in mice, with correlative data suggesting its relevance to human patients (Xia et al., 2015; Harb et al., 2020). Alveolar macrophages showed increased Jag1 expression when exposed to ultrafine ambient particles through a mechanism dependent on Aryl Hydrocarbon Receptor, in turn engaging Notch receptors in CD4 ${ }^{+}$cells (Xia et al., 2015). Surprisingly, the dominant Notch receptor in these studies of allergic airway inflammation proved to be Notch4, rather than Notch1/2 (Harb et al., 2020). Functional effects of Notch 4 on Th2 differentiation were mediated by canonical RBPJ $\kappa$-dependent Notch signaling, while other effects were not. In addition, Notch4 activation was found to predominate in Tregs, where it was linked to Wnt and Hippo activation, destabilization of the Treg program and a pro-inflammatory crosstalk with type 2 innate lymphoid cells. At this stage, the relative impact of Notch1/2-mediated and Notch4-mediated effects reported by different groups has not been resolved. Another interesting consideration is the emerging role of Notch signaling in cells other than $\mathrm{CD}^{+}{ }^{+} \mathrm{T}$ lymphocytes. Roles for Notch signaling have been reported in the regulation of lung-infiltrating effector $\mathrm{CD} 8^{+}$ $\mathrm{T}$ cells, lung-resident memory $\mathrm{CD}^{+} \mathrm{T}$ cells as well as innate lymphoid cell differentiation and function, all of which could impact asthma pathogenesis (Okamoto et al., 2008; Hombrink et al., 2016; Zhang et al., 2017). Finally, Notch is also emerging as a key regulator of bronchial epithelium homeostasis in health and disease, as continuous Jagged1/2-Notch2-mediated signals block the transdifferentiation of club cells into ciliated cells and basal epithelial stem/progenitor cells communicate with their secretory progeny via Notch signaling (Lafkas et al., 2015; Pardo-Saganta et al., 2015).

Altogether, these findings reveal the interesting and complex biology of Notch signaling in airway inflammation. The mechanisms of Notch action and all the cellular partners involved need to be investigated further, including immune and non-immune cell types. These considerations are especially relevant when systemic rather than cell-specific targeted genetic interventions are being considered in translational investigations.

\section{Other Immune and Inflammatory Disorders}

Although space limitations prevent us from comprehensively including all work reported in the field, a role for Notch signaling has been suggested in other immune and inflammatory disorders, with various degrees of evidence. An interesting common denominator is that investigations of inflammatory disorders identify complex interactions of immune cells with non-hematopoietic partners in their environment, and new functions of Notch signaling in unexpected cell types.

In inflammatory aspects of atherosclerosis, Notch may be involved in the regulation of both endothelial function and infiltrating leukocytes. Endothelial Notch1 expression was suppressed in mice and humans on high fat diets, which correlated with increased atherosclerosis progression (Briot et al., 2015). In the same study, human aortic endothelial cells treated with lipids and inflammatory cytokines showed a significant decrease in Notch1 expression. These data were consistent with an anti-inflammatory role of endothelial Notch1 signaling. In contrast, other reports reported Notch-dependent induction of IL-6 expression in endothelial cells and a crosstalk with macrophages, polarizing them to an inflammatory state via Dll4-dependent signals (Pabois et al., 2014, 2016). In a LDL-deficient mouse model of atherosclerosis, in vivo antibody-mediated Dll4 blockade attenuated the progression of atherosclerotic plaques, as well as macrophage accumulation and M1 differentiation (Fukuda et al., 2012). More work is needed to fully understand the role of Notch signaling in atherosclerosis, which could be hindered by the lack of mouse models that fully recapitulate human disease.

In rheumatoid arthritis, early work suggested the presence of activated Notch1 receptors in synovial cells, especially in vascular and perivascular regions (Nakazawa et al., 2001; Gao et al., 2012). In a mouse model of collagen-induced arthritis, GSI administration decreased the clinical and pathological severity of joint inflammation (Park et al., 2015). In recent investigations of human synovial tissue at single cell resolution, Wei and colleagues identified an expanded population of Notch3expressing sublining fibroblasts with evidence of Notch activation in rheumatoid arthritis patients (Wei et al., 2020). Singlecell transcriptomic analysis of synovial cell types suggested the existence of positional identity transmitted from the endothelium to synovial fibroblasts via Notch signaling. Indeed, organoid cultures of synovial fibroblasts and endothelial cells was consistent with a wave of Notch signaling propagated through a Jagged1/Notch3 signaling relay. These findings were reminiscent of earlier data showing a role for Notch in layering of smooth muscle cells in developing vessels, with Jagged 1 expression being induced as a Notch transcriptional target as part of a positive feedback loop (Manderfield et al., 2012). In a mouse model of antibody-mediated arthritis induced by transfer of $\mathrm{K} / \mathrm{BxN}$ mouse serum, Notch3-deficient mice were resistant to arthritis induction and anti-Notch3 neutralizing antibodies blunted disease severity (with lesser effects for anti-Notch1 antibodies) (Wei et al., 2020). These exciting new data provide an entirely new perspective on disease pathogenesis and on the development of Notch-based therapeutics in autoimmune arthritis.

\section{LESSONS AND FUTURE DIRECTIONS}

Much can be learned already from the rich biology of Notch signaling in cancer and inflammatory disorders, and from preclinical and early clinical investigations to target the Notch pathway therapeutically (Table 1).

In cancer, Notch behaves as an oncogenic pathway in a diverse range of tumors through gene translocations, mutational activation or natural interactions of the receptors with Notch ligands in the microenvironment. Notch also controls tumor 
angiogenesis via a crosstalk with the VEGF pathway. Yet, early clinical interventions attempted so far to target Notch signaling in cancer have been disappointing. Key issues include selection for resistant cells as well as on-target side effects that result from prolonged systemic inhibition of the Notch pathway or its components. On-target toxicities rooted in the physiological role of Notch in normal tissues have been dose-limiting and have prevented the deployment of maximally effective inhibition schedules, thus in turn likely contributing to decreased anti-tumor activity. Moving forward, it will be essential to better select patients with Notchsensitive tumors and consider synergistic effects of combination therapies. In addition, all efforts need to be made to identify more specific strategies to target Notch signaling or its consequences in tumor cells while sparing or protecting normal tissues, especially since prolonged inhibition remains desirable in cancer therapy.

In contrast, the role of Notch signaling in immune and inflammatory disorders represents a more recent discovery leading to new therapeutic opportunities. Of note, all information available so far stems from preclinical disease models, thus the benefits of Notch inhibition in human inflammatory disorders remains to be established. To maximize chances of success, we believe that it will be important to consider rules that differ from those applying to Notch signaling in cancer. Prolonged Notch inhibition is not always necessary to achieve long-term therapeutic benefits in immune disorders. Instead, pulses of Notch inhibition applied at critical times in the disease course can

\section{REFERENCES}

Amsen, D., Antov, A., Jankovic, D., Sher, A., Radtke, F., Souabni, A., et al. (2007). Direct regulation of Gata3 expression determines the $\mathrm{T}$ helper differentiation potential of Notch. Immunity 27, 89-99. doi: 10.1016/j.immuni.2007.05.021

Amsen, D., Blander, J. M., Lee, G. R., Tanigaki, K., Honjo, T., and Flavell, R. A. (2004). Instruction of distinct CD4 T helper cell fates by different notch ligands on antigen-presenting cells. Cell 117, 515-526. doi: 10.1016/s0092-8674(04) 00451-9

Artavanis-Tsakonas, S., Muskavitch, M. A., and Yedvobnick, B. (1983). Molecular cloning of Notch, a locus affecting neurogenesis in Drosophila melanogaster. Proc. Natl. Acad. Sci. U.S.A. 80, 1977-1981. doi: 10.1073/pnas.80.7.1977

Aster, J. C., Pear, W. S., and Blacklow, S. C. (2017). The varied roles of notch in cancer. Annu. Rev. Pathol. 12, 245-275. doi: 10.1146/annurev-pathol-052016100127

Auderset, F., Schuster, S., Coutaz, M., Koch, U., Desgranges, F., Merck, E., et al. (2012). Redundant Notch1 and Notch2 signaling is necessary for IFNgamma secretion by $\mathrm{T}$ helper 1 cells during infection with Leishmania major. PLoS Pathog. 8:e1002560. doi: 10.1371/journal.ppat.1002560

Backer, R. A., Helbig, C., Gentek, R., Kent, A., Laidlaw, B. J., Dominguez, C. X., et al. (2014). A central role for Notch in effector CD8(+) T cell differentiation. Nat. Immunol. 15, 1143-1151. doi: 10.1038/ni.3027

Bailis, W., Yashiro-Ohtani, Y., Fang, T. C., Hatton, R. D., Weaver, C. T., Artis, D., et al. (2013). Notch simultaneously orchestrates multiple helper T cell programs independently of cytokine signals. Immunity 39, 148-159. doi: 10. 1016/j.immuni.2013.07.006

Bassil, R., Zhu, B., Lahoud, Y., Riella, L. V., Yagita, H., Elyaman, W., et al. (2011). Notch ligand delta-like 4 blockade alleviates experimental autoimmune encephalomyelitis by promoting regulatory $\mathrm{T}$ cell development. J. Immunol. 187, 2322-2328. doi: 10.4049/jimmunol.1100725

Best, J. D., Smith, D. W., Reilly, M. A., O’Donnell, R., Lewis, H. D., Ellis, S., et al. (2007). The novel gamma secretase inhibitor reprogram immune cells to a less pathogenic state, or decrease immune cell trafficking to target organs, while expanding and reinforcing the function of regulatory $\mathrm{T}$ cells. In addition, selective targeting of individual Notch ligands and receptors can open a therapeutic window that does not exist with systemic pan-Notch inhibition. In some contexts, the discovery of new roles for understudied Notch pathway members, such as Notch3 and Notch4, may provide therapeutic opportunities even with prolonged inhibition, as the side effects of targeting these receptors are not predicted to be severe. Finally, combination therapies could provide other avenues, building on deeper molecular understanding of Notch signaling in immune cells.

\section{AUTHOR CONTRIBUTIONS}

FA and IM wrote and edited the manuscript. Both authors contributed to the article and approved the submitted version.

\section{FUNDING}

Research on Notch signaling in the IM laboratory is currently supported by grants from the National Institute of Allergy and Infectious Diseases (R01-AI091627) and the Leukemia and Lymphoma Society (TRP 6583-20). FA was supported by T32 funding from NCI (T32-CA009140) and an American Society of Hematology Research Restart Award.

$\mathrm{N}$-[cis-4-[(4-chlorophenyl)sulfonyl]-4-(2,5-difluorophenyl)cyclohexyl]1,1,1-trifluoromethanesulfonamide (MRK-560) reduces amyloid plaque deposition without evidence of notch-related pathology in the Tg2576 mouse. J. Pharmacol. Exp. Ther. 320, 552-558. doi: 10.1124/jpet.106. 114330

Borgegard, T., Gustavsson, S., Nilsson, C., Parpal, S., Klintenberg, R., Berg, A. L., et al. (2012). Alzheimer's disease: presenilin 2-sparing gamma-secretase inhibition is a tolerable Abeta peptide-lowering strategy. J. Neurosci. 32, 1729717305. doi: 10.1523/jneurosci.1451-12.2012

Brandstadter, J. D., and Maillard, I. (2019). Notch signalling in T cell homeostasis and differentiation. Open Biol. 9:190187. doi: 10.1098/rsob. 190187

Briot, A., Civelek, M., Seki, A., Hoi, K., Mack, J. J., Lee, S. D., et al. (2015). Endothelial NOTCH1 is suppressed by circulating lipids and antagonizes inflammation during atherosclerosis. J. Exp. Med. 212, 2147-2163. doi: 10. 1084/jem.20150603

Casulo, C., Ruan, J., Dang, N. H., Gore, L., Diefenbach, C., and Anne, W. (2016). Safety and preliminary efficacy results of a phase i first-in-human study of the novel Notch-1 Targeting antibody brontictuzumab (OMP-52M51) administered intravenously to patients with hematologic malignancies. Blood 128:5108. doi: 10.1182/blood.v128.22.5108.5108

Charbonnier, L. M., Wang, S., Georgiev, P., Sefik, E., and Chatila, T. A. (2015). Control of peripheral tolerance by regulatory $\mathrm{T}$ cell-intrinsic Notch signaling. Nat. Immunol. 16, 1162-1173. doi: 10.1038/ni. 3288

Chiorean, E. G., LoRusso, P., Strother, R. M., Diamond, J. R., Younger, A., Messersmith, W. A., et al. (2015). A Phase I first-in-human study of enoticumab (REGN421), a fully human delta-like ligand 4 (Dll4) monoclonal antibody in patients with advanced solid tumors. Clin. Cancer Res. 21, 2695-2703. doi: 10.1158/1078-0432.ccr-14-2797

Choi, W. H., Jo, H. R., Jeon, E. J., Youm, S. Y., Jeon, J. S., Son, Y. G., et al. (2016). Development, validation, and application of ELISA for detection of anti-HD105 
antibodies in pre-clinical safety evaluation using monkeys. J. Pharm. Biomed. Anal. 131, 309-315. doi: 10.1016/j.jpba.2016.09.009

Choy, L., Hagenbeek, T. J., Solon, M., French, D., Finkle, D., Shelton, A., et al. (2017). Constitutive NOTCH3 signaling promotes the growth of basal breast cancers. Cancer Res. 77, 1439-1452. doi: 10.1158/0008-5472.can-16-1022

Chung, J., Ebens, C. L., Perkey, E., Radojcic, V., Koch, U., Scarpellino, L., et al. (2017). Fibroblastic niches prime $\mathrm{T}$ cell alloimmunity through Delta-like Notch ligands. J. Clin. Invest. 127, 1574-1588. doi: 10.1172/jci89535

Chung, J., Radojcic, V., Perkey, E., Parnell, T. J., Niknafs, Y., Jin, X., et al. (2019). Early notch signals induce a pathogenic molecular signature during priming of alloantigen-specific conventional CD4(+) T cells in graft-versus-host disease. J. Immunol. 203, 557-568. doi: 10.4049/jimmunol.1900192

Churcher, I., Beher, D., Best, J. D., Castro, J. L., Clarke, E. E., Gentry, A., et al. (2006), 4 -substituted cyclohexyl sulfones as potent, orally active gamma-secretase inhibitors. Bioorg. Med. Chem. Lett. 16, 280-284. doi: 10.1016/j.bmcl.2005.10. 009

Cook, N., Basu, B., Smith, D. M., Gopinathan, A., Evans, J., Steward, W. P., et al. (2018). A phase I trial of the gamma-secretase inhibitor MK0752 in combination with gemcitabine in patients with pancreatic ductal adenocarcinoma. Br. J. Cancer 118, 793-801. doi: 10.1038/bjc.2017.495

Cullion, K., Draheim, K. M., Hermance, N., Tammam, J., Sharma, V. M., Ware, C., et al. (2009). Targeting the Notch1 and mTOR pathways in a mouse T-ALL model. Blood 113, 6172-6181. doi: 10.1182/blood-2008-02-136762

De Strooper, B., Annaert, W., Cupers, P., Saftig, P., Craessaerts, K., Mumm, J. S., et al. (1999). A presenilin-1-dependent gamma-secretase-like protease mediates release of Notch intracellular domain. Nature 398, 518-522. doi: 10.1038/19083

Deangelo, D. J., Stone, R. M., Silverman, L. B., Stock, W., Attar, E. C., Fearen, I., et al. (2006). A phase I clinical trial of the notch inhibitor MK-0752 in patients with T-cell acute lymphoblastic leukemia/lymphoma (T-ALL) and other leukemias. J. Clin. Oncol. 24, 6585-6585. doi: 10.1200/jco.2006.24.18_ suppl.6585

del Amo, F. F., Gendron-Maguire, M., Swiatek, P. J., Jenkins, N. A., Copeland, N. G., and Gridley, T. (1993). Cloning, analysis, and chromosomal localization of Notch-1, a mouse homolog of Drosophila Notch. Genomics 15, 259-264. doi: $10.1006 /$ geno. 1993.1055

Dexter, J. S. (1914). The analysis of a case of continuous variation in Drosophila by a study of its linkage relations. Am. Nat. 48, 712-758. doi: 10.1086/ 279446

Dongre, A., Surampudi, L., Lawlor, R. G., Fauq, A. H., Miele, L., Golde, T. E., et al. (2014). Non-canonical notch signaling drives activation and differentiation of peripheral CD4(+) T Cells. Front. Immunol. 5:54. doi: 10.3389/fimmu.2014. 00054

Doody, R. S., Raman, R., Farlow, M., Iwatsubo, T., Vellas, B., Joffe, S., et al. (2013). A phase 3 trial of semagacestat for treatment of Alzheimer's disease. N. Engl. J. Med. 369, 341-350. doi: 10.1056/nejmoa1210951

Eixarch, H., Mansilla, M. J., Costa, C., Kunkel, S. L., Montalban, X., Godessart, N., et al. (2013). Inhibition of delta-like ligand 4 decreases Th1/Th17 response in a mouse model of multiple sclerosis. Neurosci. Lett. 541, 161-166. doi: 10.1016/j.neulet.2013.02.038

El-Khoueiry, A. B., Desai, J., Padmanabhan Iyer, S., Gadgeel, S. M., Ramalingam, S. S., Horn, L., et al. (2018). A phase I study of AL101, a pan-NOTCH inhibitor, in patients (pts) with locally advanced or metastatic solid tumors. J. Clin. Oncol. 36, 2515-2515. doi: 10.1200/jco.2018.36.15_suppl.2515

Ellisen, L. W., Bird, J., West, D. C., Soreng, A. L., Reynolds, T. C., Smith, S. D., et al. (1991). TAN-1, the human homolog of the Drosophila notch gene, is broken by chromosomal translocations in T lymphoblastic neoplasms. Cell 66, 649-661. doi: 10.1016/0092-8674(91)90111-b

Elyaman, W., Bassil, R., Bradshaw, E. M., Orent, W., Lahoud, Y., Zhu, B., et al. (2012). Notch receptors and Smad3 signaling cooperate in the induction of interleukin-9-producing T cells. Immunity 36, 623-634. doi: 10.1016/j.immuni. 2012.01.020

Fabbri, G., Holmes, A. B., Viganotti, M., Scuoppo, C., Belver, L., Herranz, D., et al. (2017). Common nonmutational NOTCH1 activation in chronic lymphocytic leukemia. Proc. Natl. Acad. Sci. .U.S.A. 114, E2911-E2919.

Falchook, G. S., Dowlati, A., Naing, A., Gribbin, M. J., Jenkins, D. W., and Chang, L. L. (2015). Phase I study of MEDI0639 in patients with advanced solid tumors. J. Clin. Oncol. 33, 3024-3024. doi: 10.1200/jco.2015.33.15_suppl.3024
Fang, T. C., Yashiro-Ohtani, Y., Del Bianco, C., Knoblock, D. M., Blacklow, S. C., and Pear, W. S. (2007). Notch directly regulates Gata3 expression during T helper 2 cell differentiation. Immunity 27, 100-110. doi: 10.1016/j.immuni. 2007.04.018

Fasnacht, N., Huang, H. Y., Koch, U., Favre, S., Auderset, F., Chai, Q., et al. (2014). Specific fibroblastic niches in secondary lymphoid organs orchestrate distinct Notch-regulated immune responses. J. Exp. Med. 211, 2265-2279. doi: $10.1084 /$ jem. 20132528

Ferrarotto, R., Eckhardt, G., Patnaik, A., LoRusso, P., Faoro, L., Heymach, J. V., et al. (2018). A phase I dose-escalation and dose-expansion study of brontictuzumab in subjects with selected solid tumors. Ann. Oncol. 29, 15611568. doi: 10.1093/annonc/mdy171

Ferrarotto, R., Ho, A. L., Wirth, L. J., Dekel, E., Walker, R. W., and Vergara-Silva, A. L. (2019). ACCURACY: phase (P) 2 trial of AL101, a pan-Notch inhibitor, in patients (pts) with recurrent/metastatic (R/M) adenoid cystic carcinoma (ACC) with Notch activating mutations (Notchact mut). J. Clin. Oncol. 37:TS6098.

Folkman, J. (1971). Tumor angiogenesis: therapeutic implications. N. Engl. J. Med. $285,1182-1186$.

Fu, W., Lei, C., Yu, Y., Liu, S., Li, T., Lin, F., et al. (2019). EGFR/Notch antagonists enhance the response to inhibitors of the PI3K-Akt pathway by decreasing tumor-initiating cell frequency. Clin. Cancer Res. 25, 2835-2847. doi: 10.1158/ 1078-0432.ccr- 18-2732

Fukuda, D., Aikawa, E., Swirski, F. K., Novobrantseva, T. I., Kotelianski, V., Gorgun, C. Z., et al. (2012). Notch ligand delta-like 4 blockade attenuates atherosclerosis and metabolic disorders. Proc. Natl. Acad. Sci. U.S.A. 109, E1868-E1877.

Gao, W., Sweeney, C., Connolly, M., Kennedy, A., Ng, C. T., McCormick, J., et al. (2012). Notch-1 mediates hypoxia-induced angiogenesis in rheumatoid arthritis. Arthritis Rheum 64, 2104-2113. doi: 10.1002/art.34397

Haass, C., and Selkoe, D. J. (1993). Cellular processing of beta-amyloid precursor protein and the genesis of amyloid beta-peptide. Cell 75, 1039-1042. doi: 10.1016/0092-8674(93)90312-e

Habets, R. A., de Bock, C. E., Serneels, L., Lodewijckx, I., Verbeke, D., Nittner, D., et al. (2019). Safe targeting of $\mathrm{T}$ cell acute lymphoblastic leukemia by pathology-specific NOTCH inhibition. Sci. Transl. Med. 11:eaau6246. doi: 10.1126/scitranslmed.aau6246

Harb, H., Stephen-Victor, E., Crestani, E., Benamar, M., Massoud, A., Cui, Y., et al. (2020). A regulatory T cell Notch4-GDF15 axis licenses tissue inflammation in asthma. Nat. Immunol. 21, 1359-1370. doi: 10.1038/s41590-020-0777-3

Hombrink, P., Helbig, C., Backer, R. A., Piet, B., Oja, A. E., Stark, R., et al. (2016). Programs for the persistence, vigilance and control of human CD8(+) lung-resident memory T cells. Nat. Immunol. 17, 1467-1478. doi: 10.1038/ni. 3589

Hozumi, K., Mailhos, C., Negishi, N., Hirano, K., Yahata, T., Ando, K., et al. (2008). Delta-like 4 is indispensable in thymic environment specific for T cell development. J. Exp. Med. 205, 2507-2513. doi: 10.1084/jem.20080134

Hu, S., Fu, W., Li, T., Yuan, Q., Wang, F., Lv, G., et al. (2017). Antagonism of EGFR and Notch limits resistance to EGFR inhibitors and radiation by decreasing tumor-initiating cell frequency. Sci. Transl. Med. 9:eaag0339. doi: 10.1126/scitranslmed.aag0339

Hu, Z. I., Bendell, J. C., Bullock, A., LoConte, N. K., Hatoum, H., Ritch, P., et al. (2019). A randomized phase II trial of nab-paclitaxel and gemcitabine with tarextumab or placebo in patients with untreated metastatic pancreatic cancer. Cancer Med. 8, 5148-5157. doi: 10.1002/cam4.2425

Huang, M. T., Chen, Y. L., Lien, C. I., Liu, W. L., Hsu, L. C., Yagita, H., et al. (2017). Notch ligand DLL4 alleviates allergic airway inflammation via induction of a homeostatic regulatory pathway. Sci. Rep. 7:43535.

Hurtado, C., Safarova, A., Smith, M., Chung, R., Bruyneel, A. A. N., GomezGaleno, J., et al. (2019). Disruption of NOTCH signaling by a small molecule inhibitor of the transcription factor RBPJ. Sci. Rep. 9:10811.

Jenkins, D. W., Ross, S., Veldman-Jones, M., Foltz, I. N., Clavette, B. C., Manchulenko, K., et al. (2012). MEDI0639: a novel therapeutic antibody targeting Dll4 modulates endothelial cell function and angiogenesis in vivo. Mol. Cancer Ther. 11, 1650-1660. doi: 10.1158/1535-7163.mct-11-1027

Jia, X., Wang, W., Xu, Z., Wang, S., Wang, T., Wang, M., et al. (2016). A humanized anti-DLL4 antibody promotes dysfunctional angiogenesis and inhibits breast tumor growth. Sci. Rep. 6:27985. 
Jimeno, A., Moore, K. N., Gordon, M., Chugh, R., Diamond, J. R., Aljumaily, R., et al. (2019). A first-in-human phase 1a study of the bispecific anti-DLL4/antiVEGF antibody navicixizumab (OMP-305B83) in patients with previously treated solid tumors. Invest. New Drugs 37, 461-472. doi: 10.1007/s10637-0180665-y

Jurynczyk, M., Jurewicz, A., Bielecki, B., Raine, C. S., and Selmaj, K. (2005). Inhibition of Notch signaling enhances tissue repair in an animal model of multiple sclerosis. J. Neuroimmunol. 170, 3-10. doi: 10.1016/j.jneuroim.2005. 10.013

Kang, J. H., Kim, B. S., Uhm, T. G., Lee, S. H., Lee, G. R., Park, C. S., et al. (2009). Gamma-secretase inhibitor reduces allergic pulmonary inflammation by modulating Th1 and Th2 responses. Am. J. Respir. Crit. Care Med. 179, 875-882. doi: 10.1164/rccm.200806-893oc

Keck, P. J., Hauser, S. D., Krivi, G., Sanzo, K., Warren, T., Feder, J., et al. (1989). Vascular permeability factor, an endothelial cell mitogen related to PDGF. Science 246, 1309-1312. doi: 10.1126/science.2479987

Kim, D. H., Lee, S., Kang, H. G., Park, H. W., Lee, H. W., Kim, D., et al. (2020). Synergistic antitumor activity of a DLL4/VEGF bispecific therapeutic antibody in combination with irinotecan in gastric cancer. BMB Rep. 53, 533-538. doi: 10.5483/bmbrep.2020.53.10.103

Kimberly, W. T., LaVoie, M. J., Ostaszewski, B. L., Ye, W., Wolfe, M. S., and Selkoe, D. J. (2003). Gamma-secretase is a membrane protein complex comprised of presenilin, nicastrin. Aph-1, and Pen-2. Proc. Natl. Acad. Sci. U.S.A. 100, 6382-6387. doi: 10.1073/pnas.1037392100

KleinJan, A., Tindemans, I., Montgomery, J. E., Lukkes, M., de Bruijn, M. J. W., van Nimwegen, M., et al. (2018). The Notch pathway inhibitor stapled alpha-helical peptide derived from mastermind-like 1 (SAHM1) abrogates the hallmarks of allergic asthma. J. Allergy Clin. Immunol. 142, 76.e8-85.e8.

Knoechel, B., Roderick, J. E., Williamson, K. E., Zhu, J., Lohr, J. G., Cotton, M. J., et al. (2014). An epigenetic mechanism of resistance to targeted therapy in $\mathrm{T}$ cell acute lymphoblastic leukemia. Nat. Genet. 46, 364-370.

Koch, U., Fiorini, E., Benedito, R., Besseyrias, V., Schuster-Gossler, K., Pierres, M., et al. (2008). Delta-like 4 is the essential, nonredundant ligand for Notch1 during thymic T cell lineage commitment. J. Exp. Med. 205, 2515-2523. doi: 10.1084/jem.20080829

Kopan, R., and Ilagan, M. X. (2009). The canonical Notch signaling pathway: unfolding the activation mechanism. Cell 137, 216-233. doi: 10.1016/j.cell. 2009.03.045

Kovall, R. A., Gebelein, B., Sprinzak, D., and Kopan, R. (2017). The canonical notch signaling pathway: structural and biochemical insights into shape. Sugar, and Force. Dev. Cell 41, 228-241. doi: 10.1016/j.devcel.2017.04.001

Kummar, S., Do, K. T., O'Sullivan Coyne, G. H., Turkbey, B., Meltzer, P. S., and Polley, E. (2015). Phase II trial of PF-03084014 in adults with desmoid tumors/aggressive fibromatosis. J. Clin. Oncol. 33:10563. doi: 10.1200/jco.2015. 33.15_suppl.10563

Lafkas, D., Shelton, A., Chiu, C., de Leon Boenig, G., Chen, Y., Stawicki, S. S., et al. (2015). Therapeutic antibodies reveal Notch control of transdifferentiation in the adult lung. Nature 528, 127-131. doi: 10.1038/nature15715

Laky, K., Evans, S., Perez-Diez, A., and Fowlkes, B. J. (2015). Notch signaling regulates antigen sensitivity of naive $\mathrm{CD} 4+\mathrm{T}$ cells by tuning co-stimulation. Immunity 42, 80-94. doi: 10.1016/j.immuni.2014.12.027

Lardelli, M., Dahlstrand, J., and Lendahl, U. (1994). The novel Notch homologue mouse Notch 3 lacks specific epidermal growth factor-repeats and is expressed in proliferating neuroepithelium. Mech. Dev. 46, 123-136. doi: 10.1016/09254773(94)90081-7

Lee, D., Kim, D., Choi, Y. B., Kang, K., Sung, E. S., Ahn, J. H., et al. (2016). Simultaneous blockade of VEGF and Dll4 by HD105, a bispecific antibody, inhibits tumor progression and angiogenesis. MAbs 8, 892-904. doi: 10.1080/ 19420862.2016.1171432

Lee, S. M., Moon, J., Redman, B. G., Chidiac, T., Flaherty, L. E., Zha, Y., et al. (2015). Phase 2 study of RO4929097, a gamma-secretase inhibitor, in metastatic melanoma: SWOG 0933. Cancer 121, 432-440. doi: 10.1002/cncr.29055

Lehal, R., Zaric, J., Vigolo, M., Urech, C., Frismantas, V., Zangger, N., et al. (2020). Pharmacological disruption of the Notch transcription factor complex. Proc. Natl. Acad. Sci. U.S.A. 117, 16292-16301. doi: 10.1073/pnas.1922606117

Leung, D. W., Cachianes, G., Kuang, W. J., Goeddel, D. V., and Ferrara, N. (1989). Vascular endothelial growth factor is a secreted angiogenic mitogen. Science 246, 1306-1309. doi: 10.1126/science. 2479986
Lewis, K. L., Caton, M. L., Bogunovic, M., Greter, M., Grajkowska, L. T., Ng, D., et al. (2011). Notch2 receptor signaling controls functional differentiation of dendritic cells in the spleen and intestine. Immunity 35, 780-791. doi: 10.1016/ j.immuni.2011.08.013

Li, Y., Hickson, J. A., Ambrosi, D. J., Haasch, D. L., Foster-Duke, K. D., Eaton, L. J., et al. (2018). ABT-165, a dual variable domain immunoglobulin (DVDIg) Targeting DLL4 and VEGF, demonstrates superior efficacy and favorable safety profiles in preclinical models. Mol. Cancer Ther. 17, 1039-1050. doi: 10.1158/1535-7163.mct-17-0800

Liang, W. C., Wu, X., Peale, F. V., Lee, C. V., Meng, Y. G., Gutierrez, J., et al. (2006). Cross-species vascular endothelial growth factor (VEGF)-blocking antibodies completely inhibit the growth of human tumor xenografts and measure the contribution of stromal VEGF. J. Biol. Chem. 281, 951-961. doi: 10.1074/jbc. m508199200

Lopez-Lopez, S., Monsalve, E. M., Romero de Avila, M. J., Gonzalez-Gomez, J., Hernandez de Leon, N., Ruiz-Marcos, F., et al. (2020). NOTCH3 signaling is essential for NF-kappaB activation in TLR-activated macrophages. Sci. Rep. $10: 14839$.

Luistro, L., He, W., Smith, M., Packman, K., Vilenchik, M., Carvajal, D., et al. (2009). Preclinical profile of a potent gamma-secretase inhibitor targeting notch signaling with in vivo efficacy and pharmacodynamic properties. Cancer Res. 69 , 7672-7680. doi: 10.1158/0008-5472.can-09-1843

Magee, C. N., Murakami, N., Borges, T. J., Shimizu, T., Safa, K., Ohori, S., et al. (2019). Notch-1 inhibition promotes immune regulation in transplantation via regulatory T Cell-dependent mechanisms. Circulation 140, 846-863. doi: 10.1161/circulationaha.119.040563

Maillard, I., Weng, A. P., Carpenter, A. C., Rodriguez, C. G., Sai, H., Xu, L., et al. (2004). Mastermind critically regulates Notch-mediated lymphoid cell fate decisions. Blood 104, 1696-1702. doi: 10.1182/blood-2004-020514

Mancarella, S., Serino, G., Dituri, F., Cigliano, A., Ribback, S., Wang, J., et al. (2020). Crenigacestat, a selective NOTCH1 inhibitor, reduces intrahepatic cholangiocarcinoma progression by blocking VEGFA/DLL4/MMP13 axis. Cell Death Differ. 27, 2330-2343. doi: 10.1038/s41418-020-0505-4

Manderfield, L. J., High, F. A., Engleka, K. A., Liu, F., Li, L., Rentschler, S., et al. (2012). Notch activation of Jagged 1 contributes to the assembly of the arterial wall. Circulation 125, 314-323. doi: 10.1161/circulationaha.111.047159

Massard, C., Azaro, A., Soria, J. C., Lassen, U., Le Tourneau, C., Sarker, D., et al. (2018). First-in-human study of LY3039478, an oral Notch signaling inhibitor in advanced or metastatic cancer. Ann. Oncol. 29, 1911-1917. doi: 10.1093/ annonc/mdy244

McKeage, M. J., Kotasek, D., Markman, B., Hidalgo, M., Millward, M. J., Jameson, M. B., et al. (2018). Phase IB trial of the anti-cancer stem cell DLL4-binding agent demcizumab with pemetrexed and carboplatin as first-line treatment of metastatic non-squamous NSCLC. Targeted Oncol.y 13, 89-98. doi: 10.1007/ s11523-017-0543-0

Messersmith, W. A., Shapiro, G. I., Cleary, J. M., Jimeno, A., Dasari, A., Huang, B., et al. (2015). A Phase I, dose-finding study in patients with advanced solid malignancies of the oral gamma-secretase inhibitor PF-03084014. Clin. Cancer Res. 21, 60-67. doi: 10.1158/1078-0432.ccr-14-0607

Minter, L. M., Turley, D. M., Das, P., Shin, H. M., Joshi, I., Lawlor, R. G., et al. (2005). Inhibitors of gamma-secretase block in vivo and in vitro $\mathrm{T}$ helper type 1 polarization by preventing Notch upregulation of Tbx21. Nat. Immunol. 6 , 680-688. doi: $10.1038 /$ ni1209x

Mochizuki, K., Xie, F., He, S., Tong, Q., Liu, Y., Mochizuki, I., et al. (2013). Delta-like ligand 4 identifies a previously uncharacterized population of inflammatory dendritic cells that plays important roles in eliciting allogeneic $\mathrm{T}$ cell responses in mice. J. Immunol. 190, 3772-3782. doi: 10.4049/jimmunol.120 2820

Moellering, R. E., Cornejo, M., Davis, T. N., Del Bianco, C., Aster, J. C., Blacklow, S. C., et al. (2009). Direct inhibition of the NOTCH transcription factor complex. Nature 462, 182-188. doi: 10.1038/nature08543

Morgan, T. H. (1917). The theory of the gene. Am. Nat. 51, 513-544.

Morohashi, Y., Kan, T., Tominari, Y., Fuwa, H., Okamura, Y., Watanabe, N., et al. (2006). C-terminal fragment of presenilin is the molecular target of a dipeptidic $\gamma$-secretase-specific inhibitor DAPT (N-[N-(3,5Difluorophenacetyl)-L-alanyl]-S-phenylglycine t-Butyl Ester)*. J. Biol. Chem. 281, 14670-14676. doi: 10.1074/jbc.m513012200 
Nakazawa, M., Ishii, H., Aono, H., Takai, M., Honda, T., Aratani, S., et al. (2001). Role of Notch-1 intracellular domain in activation of rheumatoid synoviocytes. Arthritis Rheum 44, 1545-1554. doi: 10.1002/1529-0131(200107)44:7<1545: aid-art278>3.0.co;2-q

Nam, Y., Sliz, P., Song, L., Aster, J. C., and Blacklow, S. C. (2006). Structural basis for cooperativity in recruitment of MAML coactivators to Notch transcription complexes. Cell 124, 973-983. doi: 10.1016/j.cell.2005. 12.037

Noguera-Troise, I., Daly, C., Papadopoulos, N. J., Coetzee, S., Boland, P., Gale, N. W., et al. (2006). Blockade of Dll4 inhibits tumour growth by promoting nonproductive angiogenesis. Nature 444, 1032-1037. doi: 10.1038/nature05355

Okamoto, M., Takeda, K., Joetham, A., Ohnishi, H., Matsuda, H., Swasey, C. H., et al. (2008). Essential role of Notch signaling in effector memory CD8+ T cell-mediated airway hyperresponsiveness and inflammation. J. Exp. Med. 205, 1087-1097. doi: 10.1084/jem.20072200

Osborne, B. A., and Minter, L. M. (2007). Notch signalling during peripheral T-cell activation and differentiation. Nat. Rev. Immunol. 7, 64-75. doi: 10.1038/ nri1998

Pabois, A., Devalliere, J., Quillard, T., Coulon, F., Gerard, N., Laboisse, C., et al. (2014). The disintegrin and metalloproteinase ADAM10 mediates a canonical Notch-dependent regulation of IL-6 through Dll4 in human endothelial cells. Biochem. Pharmacol. 91, 510-521. doi: 10.1016/j.bcp.2014.08.007

Pabois, A., Pagie, S., Gerard, N., Laboisse, C., Pattier, S., Hulin, P., et al. (2016). Notch signaling mediates crosstalk between endothelial cells and macrophages via Dll4 and IL6 in cardiac microvascular inflammation. Biochem. Pharmacol. 104, 95-107. doi: 10.1016/j.bcp.2016.01.016

Palomero, T., Sulis, M. L., Cortina, M., Real, P. J., Barnes, K., Ciofani, M., et al. (2007). Mutational loss of PTEN induces resistance to NOTCH1 inhibition in T-cell leukemia. Nat. Med. 13, 1203-1210. doi: 10.1038/nm1636

Pant, S., Jones, S. F., Kurkjian, C. D., Infante, J. R., Moore, K. N., Burris, H. A., et al. (2016). A first-in-human phase I study of the oral Notch inhibitor. LY900009, in patients with advanced cancer. Eur. J. Cancer 56, 1-9. doi: 10.1016/j.ejca.2015. 11.021

Pardo-Saganta, A., Tata, P. R., Law, B. M., Saez, B., Chow, R. D., Prabhu, M., et al. (2015). Parent stem cells can serve as niches for their daughter cells. Nature 523, 597-601. doi: 10.1038/nature14553

Park, J. S., Kim, S. H., Kim, K., Jin, C. H., Choi, K. Y., Jang, J., et al. (2015). Inhibition of notch signalling ameliorates experimental inflammatory arthritis. Ann. Rheum Dis. 74, 267-274. doi: 10.1136/annrheumdis-2013-203467

Perez-Fidalgo, J. A., Ortega, B., Simon, S., Samartzis, E. P., and Boussios, S. (2020). NOTCH signalling in ovarian cancer angiogenesis. Ann. Transl. Med. 8:1705. doi: $10.21037 /$ atm-20-4497

Perkey, E., Maurice De Sousa, D., Carrington, L., Chung, J., Dils, A., Granadier, D., et al. (2020). GCNT1-Mediated O-Glycosylation of the Sialomucin CD43 Is a Sensitive Indicator of Notch Signaling in Activated T Cells. J. Immunol. 204, 1674-1688. doi: 10.4049/jimmunol.1901194

Petcherski, A. G., and Kimble, J. (2000). LAG-3 is a putative transcriptional activator in the C. elegans Notch pathway. Nature 405, 364-368. doi: 10.1038/ 35012645

Pietanza, M. C., Spira, A. I., Jotte, R. M., Gadgeel, S. M., Mita, A. C., Gluck, L. L. H. W. L., et al. (2015). Final results of phase Ib of tarextumab (TRXT, OMP59R5, anti-Notch2/3) in combination with etoposide and platinum (EP) in patients (pts) with untreated extensive-stage small-cell lung cancer (ED-SCLC). J. Clin. Oncol. 33, 7508-7508. doi: 10.1200/jco.2015.33.15_suppl.7508

Pui, J. C., Allman, D., Xu, L., DeRocco, S., Karnell, F. G., Bakkour, S., et al. (1999). Notch1 expression in early lymphopoiesis influences B versus T lineage determination. Immunity 11, 299-308. doi: 10.1016/s1074-7613(00)80105-3

Radojcic, V., Paz, K., Chung, J., Du, J., Perkey, E. T., Flynn, R., et al. (2018). Notch signaling mediated by Delta-like ligands 1 and 4 controls the pathogenesis of chronic GVHD in mice. Blood 132, 2188-2200. doi: 10.1182/blood-2018-03841155

Radtke, F., Fasnacht, N., and Macdonald, H. R. (2010). Notch signaling in the immune system. Immunity 32, 14-27. doi: 10.1016/j.immuni.2010.01.004

Radtke, F., Wilson, A., Stark, G., Bauer, M., van Meerwijk, J., MacDonald, H. R., et al. (1999). Deficient $\mathrm{T}$ cell fate specification in mice with an induced inactivation of Notch1. Immunity 10, 547-558. doi: 10.1016/s1074-7613(00) 80054-0
Ramakrishnan, V., Ansell, S., Haug, J., Grote, D., Kimlinger, T., Stenson, M., et al. (2012). MRK003, a $\gamma$-secretase inhibitor exhibits promising in vitro pre-clinical activity in multiple myeloma and non-Hodgkin's lymphoma. Leukemia 26, 340-348. doi: 10.1038/leu.2011.192

Real, P. J., Tosello, V., Palomero, T., Castillo, M., Hernando, E., de Stanchina, E., et al. (2009). Gamma-secretase inhibitors reverse glucocorticoid resistance in $\mathrm{T}$ cell acute lymphoblastic leukemia. Nat. Med. 15, 50-58. doi: 10.1038/nm.1900

Reynolds, N. D., Lukacs, N. W., Long, N., and Karpus, W. J. (2011). Deltalike ligand 4 regulates central nervous system $\mathrm{T}$ cell accumulation during experimental autoimmune encephalomyelitis. J. Immunol. 187, 2803-2813. doi: 10.4049/jimmunol.1100160

Riccio, O., van Gijn, M. E., Bezdek, A. C., Pellegrinet, L., van Es, J. H., ZimberStrobl, U., et al. (2008). Loss of intestinal crypt progenitor cells owing to inactivation of both Notch1 and Notch2 is accompanied by derepression of CDK inhibitors p27Kip1 and p57Kip2. EMBO Rep. 9, 377-383. doi: 10.1038/ embor.2008.7

Ridgway, J., Zhang, G., Wu, Y., Stawicki, S., Liang, W. C., Chanthery, Y., et al. (2006). Inhibition of Dll4 signalling inhibits tumour growth by deregulating angiogenesis. Nature 444, 1083-1087. doi: 10.1038/nature05313

Riella, L. V., Ueno, T., Batal, I., De Serres, S. A., Bassil, R., Elyaman, W., et al. (2011). Blockade of Notch ligand deltal promotes allograft survival by inhibiting alloreactive Th1 cells and cytotoxic T cell generation. J. Immunol. 187, 4629-4638. doi: 10.4049/jimmunol.1004076

Riella, L. V., Yang, J., Chock, S., Safa, K., Magee, C. N., Vanguri, V., et al. (2013). Jagged2-signaling promotes IL-6-dependent transplant rejection. Eur. J. Immunol. 43, 1449-1458. doi: 10.1002/eji.20124 3151

Roderick, J. E., Gonzalez-Perez, G., Kuksin, C. A., Dongre, A., Roberts, E. R., Srinivasan, J., et al. (2013). Therapeutic targeting of NOTCH signaling ameliorates immune-mediated bone marrow failure of aplastic anemia. J. Exp. Med. 210, 1311-1329. doi: 10.1084/jem.20112615

Sahebjam, S., Bedard, P. L., Castonguay, V., Chen, Z., Reedijk, M., Liu, G., et al. (2013). A phase I study of the combination of ro4929097 and cediranib in patients with advanced solid tumours (PJC-004/NCI 8503). Br. J. Cancer 109, 943-949. doi: 10.1038/bjc.2013.380

Saito, T., Chiba, S., Ichikawa, M., Kunisato, A., Asai, T., Shimizu, K., et al. (2003). Notch2 is preferentially expressed in mature B cells and indispensable for marginal zone B lineage development. Immunity 18, 675-685. doi: 10.1016/ s1074-7613(03)00111-0

Samon, J. B., Castillo-Martin, M., Hadler, M., Ambesi-Impiobato, A., Paietta, E., Racevskis, J., et al. (2012). Preclinical analysis of the gamma-secretase inhibitor PF-03084014 in combination with glucocorticoids in T-cell acute lymphoblastic leukemia. Mol. Cancer Ther. 11, 1565-1575. doi: 10.1158/1535-7163.mct-110938

Sanchez-Martin, M., Ambesi-Impiombato, A., Qin, Y., Herranz, D., Bansal, M., Girardi, T., et al. (2017). Synergistic antileukemic therapies in NOTCH1induced T-ALL. Proc. Natl. Acad. Sci. U.S.A. 114, 2006-2011. doi: 10.1073/pnas. 1611831114

Sandy, A. R., Chung, J., Toubai, T., Shan, G. T., Tran, I. T., Friedman, A., et al. (2013a). T cell-specific notch inhibition blocks graft-versus-host disease by inducing a hyporesponsive program in alloreactive CD4+ and CD8+ T cells. J. Immunol. 190, 5818-5828. doi: 10.4049/jimmunol.1203452

Sandy, A. R., Stoolman, J., Malott, K., Pongtornpipat, P., Segal, B. M., and Maillard, I. (2013b). Notch signaling regulates T cell accumulation and function in the central nervous system during experimental autoimmune encephalomyelitis. J. Immunol. 191, 1606-1613. doi: 10.4049/jimmunol.1301116

Sato, T., van Es, J. H., Snippert, H. J., Stange, D. E., Vries, R. G., van den Born, M., et al. (2011). Paneth cells constitute the niche for Lgr5 stem cells in intestinal crypts. Nature 469, 415-418. doi: 10.1038/nature09637

Satpathy, A. T., Briseno, C. G., Lee, J. S., Ng, D., Manieri, N. A., Kc, W., et al. (2013). Notch2-dependent classical dendritic cells orchestrate intestinal immunity to attaching-and-effacing bacterial pathogens. Nat. Immunol. 14, 937-948. doi: 10.1038/ni.2679

Schaller, M. A., Neupane, R., Rudd, B. D., Kunkel, S. L., Kallal, L. E., Lincoln, P., et al. (2007). Notch ligand Delta-like 4 regulates disease pathogenesis during respiratory viral infections by modulating Th2 cytokines. J. Exp. Med. 204, 2925-2934. doi: $10.1084 /$ jem.20070661 
Shin, H. M., Minter, L. M., Cho, O. H., Gottipati, S., Fauq, A. H., Golde, T. E., et al. (2006). Notch1 augments NF-kappaB activity by facilitating its nuclear retention. EMBO J. 25, 129-138. doi: 10.1038/sj.emboj.7600902

Shin, H. M., Tilahun, M. E., Cho, O. H., Chandiran, K., Kuksin, C. A., Keerthivasan, S., et al. (2014). NOTCH1 Can Initiate NFkappaB activation via cytosolic interactions with components of the T Cell Signalosome. Front. Immunol. 5:249. doi: 10.3389/fimmu.2014. 00249

Smith, D. C., Eisenberg, P. D., Manikhas, G., Chugh, R., Gubens, M. A., Stagg, R. J., et al. (2014). A phase I dose escalation and expansion study of the anticancer stem cell agent demcizumab (anti-DLL4) in patients with previously treated solid tumors. Clin. Cancer Res. 20, 6295-6303. doi: 10.1158/1078-0432.ccr-141373

Sosa Iglesias, V., Giuranno, L., Dubois, L. J., Theys, J., and Vooijs, M. (2018). Drug resistance in non-small cell lung cancer: a potential for NOTCH targeting? Front. Oncol. 8:267. doi: 10.3389/fonc.2018.00267

Sparling, D. P., McCullough, N., Pajvani, U., and Humphrey, M. B. (2020). Inhibition of $\gamma$-secretase in adipocytes leads to altered IL-6 secretion and adipose inflammation. Adipocyte 9, 326-335. doi: 10.1080/21623945.2020. 1788235

Takam Kamga, P., Dal Collo, G., Midolo, M., Adamo, A., Delfino, P., Mercuri, A., et al. (2019). Inhibition of notch signaling enhances chemosensitivity in b-cell precursor acute lymphoblastic leukemia. Cancer Res. 79, 639-649. doi: 10.1158/0008-5472.can-18-1617

Tamura, K., Taniguchi, Y., Minoguchi, S., Sakai, T., Tun, T., Furukawa, T., et al. (1995). Physical interaction between a novel domain of the receptor Notch and the transcription factor RBP-J kappa/Su(H). Curr. Biol. 5, 1416-1423. doi: 10.1016/s0960-9822(95)00279-x

Tanaka, S., Nakada, M., Yamada, D., Nakano, I., Todo, T., Ino, Y., et al. (2015). Strong therapeutic potential of $\gamma$-secretase inhibitor MRK003 for CD44-high and CD133-low glioblastoma initiating cells. J. Neuro Oncol. 121, 239-250. doi: 10.1007/s11060-014-1630-z

Tanaka, S., Tsukada, J., Suzuki, W., Hayashi, K., Tanigaki, K., Tsuji, M., et al. (2006). The interleukin-4 enhancer CNS-2 is regulated by Notch signals and controls initial expression in NKT cells and memory-type CD4 T cells. Immunity 24, 689-701. doi: 10.1016/j.immuni.2006.04.009

Tanigaki, K., Han, H., Yamamoto, N., Tashiro, K., Ikegawa, M., Kuroda, K., et al. (2002). Notch-RBP-J signaling is involved in cell fate determination of marginal zone B cells. Nat. Immunol. 3, 443-450. doi: 10.1038/ni793

Tatarek, J., Cullion, K., Ashworth, T., Gerstein, R., Aster, J. C., and Kelliher, M. A. (2011). Notch1 inhibition targets the leukemia-initiating cells in a Tal1/Lmo2 mouse model of T-ALL. Blood 118, 1579-1590. doi: 10.1182/blood-2010-08300343

Tindemans, I., van Schoonhoven, A., KleinJan, A., de Bruijn, M. J., Lukkes, M., van Nimwegen, M., et al. (2020). Notch signaling licenses allergic airway inflammation by promoting Th2 cell lymph node egress. J. Clin. Invest. 130, 3576-3591. doi: 10.1172/jci128310

Tkachev, V., Kuhnert, F., Furlan, S. N., Zheng, H., Hunt, D. J., Colonna, L., et al. (2018). Pharmacologic blockade of Notch/Delta-like ligand 4 signaling protects from gastrointestinal acute graft-versus-host disease in non-human primates. Blood 132:2027. doi: 10.1182/blood-2018-99-110030

Tran, I. T., Sandy, A. R., Carulli, A. J., Ebens, C., Chung, J., Shan, G. T., et al. (2013). Blockade of individual Notch ligands and receptors controls graft-versus-host disease. J. Clin. Invest. 123, 1590-1604. doi: 10.1172/jci 65477

Tu, L., Fang, T. C., Artis, D., Shestova, O., Pross, S. E., Maillard, I., et al. (2005). Notch signaling is an important regulator of type 2 immunity. J. Exp. Med, 202, 1037-1042. doi: 10.1084/jem.20050923

Uyttendaele, H., Marazzi, G., Wu, G., Yan, Q., Sassoon, D., and Kitajewski, J. (1996). Notch4/int-3, a mammary proto-oncogene, is an endothelial cellspecific mammalian Notch gene. Development 122, 2251-2259. doi: 10.1242/ dev.122.7.2251

van Es, J. H., van Gijn, M. E., Riccio, O., van den Born, M., Vooijs, M., Begthel, H., et al. (2005). Notch/gamma-secretase inhibition turns proliferative cells in intestinal crypts and adenomas into goblet cells. Nature 435, 959-963. doi: 10.1038/nature03659

VanDussen, K. L., Carulli, A. J., Keeley, T. M., Patel, S. R., Puthoff, B. J., Magness, S. T., et al. (2012). Notch signaling modulates proliferation and differentiation of intestinal crypt base columnar stem cells. Development 139, 488-497. doi: 10.1242/dev.070763

Vigouroux, S., Yvon, E., Wagner, H. J., Biagi, E., Dotti, G., Sili, U., et al. (2003). Induction of antigen-specific regulatory $\mathrm{T}$ cells following overexpression of a Notch ligand by human B lymphocytes. J. Virol. 77, 10872-10880. doi: 10.1128/ jvi.77.20.10872-10880.2003

Wainberg, Z., Strickler, J., Gordon, M., Barve, M., Wang, L., Yue, H., et al. (2018). P-234 - Phase 1b open-label study evaluating the safety, pharmacokinetics, and preliminary efficacy of ABT-165 plus FOLFIRI in patients with second-line (2L) colorectal cancer (CRC). Ann. Oncol. 29:v66. doi: 10.1093/annonc/mdy151.233

Wei, K., Korsunsky, I., Marshall, J. L., Gao, A., Watts, G. F. M., Major, T., et al. (2020). Notch signalling drives synovial fibroblast identity and arthritis pathology. Nature 582, 259-264. doi: 10.1038/s41586-020-2222-z

Weinmaster, G., Roberts, V. J., and Lemke, G. (1992). Notch2: a second mammalian Notch gene. Development 116, 931-941. doi: 10.1242/dev.116.4.931

Weng, A. P., Ferrando, A. A., Lee, W., Morris, J. P. IV, Silverman, L. B., SanchezIrizarry, C., et al. (2004). Activating mutations of NOTCH1 in human T cell acute lymphoblastic leukemia. Science 306, 269-271. doi: 10.1126/science. 1102160

Weng, A. P., Millholland, J. M., Yashiro-Ohtani, Y., Arcangeli, M. L., Lau, A., Wai, C., et al. (2006). c-Myc is an important direct target of Notch1 in T-cell acute lymphoblastic leukemia/lymphoma. Genes Dev. 20, 2096-2109. doi: 10.1101/ gad.1450406

Whitehead, J., Thygesen, H., Jaki, T., Davies, S., Halford, S., Turner, H., et al. (2012). A novel Phase I/IIa design for early phase oncology studies and its application in the evaluation of MK-0752 in pancreatic cancer. Stat. Med. 31, 1931-1943. doi: 10.1002/sim.5331

Wilson, J. J., and Kovall, R. A. (2006). Crystal structure of the CSL-Notchmastermind ternary complex bound to DNA. Cell 124, 985-996. doi: 10.1016/ j.cell.2006.01.035

Wolfe, M. S. (2020). Unraveling the complexity of gamma-secretase. Semin. Cell Dev. Biol. 105, 3-11. doi: 10.1016/j.semcdb.2020.01.005

Wong, K. K., Carpenter, M. J., Young, L. L., Walker, S. J., McKenzie, G., Rust, A. J., et al. (2003). Notch ligation by Deltal inhibits peripheral immune responses to transplantation antigens by a CD8+ cell-dependent mechanism. J. Clin. Invest. 112, 1741-1750. doi: 10.1172/jci200318020

Wood, S., Feng, J., Chung, J., Radojcic, V., Sandy-Sloat, A. R., Friedman, A., et al. (2015). Transient blockade of delta-like Notch ligands prevents allograft rejection mediated by cellular and humoral mechanisms in a mouse model of heart transplantation. J. Immunol. 194, 2899-2908. doi: 10.4049/jimmunol. 1402034

Wu, L., Aster, J. C., Blacklow, S. C., Lake, R., Artavanis-Tsakonas, S., and Griffin, J. D. (2000). MAML1, a human homologue of Drosophila mastermind, is a transcriptional co-activator for NOTCH receptors. Nat. Genet. 26, 484-489. doi: $10.1038 / 82644$

Wu, Y., Cain-Hom, C., Choy, L., Hagenbeek, T. J., de Leon, G. P., Chen, Y., et al. (2010). Therapeutic antibody targeting of individual Notch receptors. Nature 464, 1052-1057. doi: 10.1038/nature08878

Xia, M., Viera-Hutchins, L., Garcia-Lloret, M., Noval Rivas, M., Wise, P., McGhee, S. A., et al. (2015). Vehicular exhaust particles promote allergic airway inflammation through an aryl hydrocarbon receptor-notch signaling cascade. J. Allergy Clin. Immunol. 136, 441-453. doi: 10.1016/j.jaci.2015.02.014

Xu, Z., Wang, Z., Jia, X., Wang, L., Chen, Z., Wang, S., et al. (2016). MMGZ01, an anti-DLL4 monoclonal antibody, promotes nonfunctional vessels and inhibits breast tumor growth. Cancer Lett. 372, 118-127. doi: 10.1016/j.canlet.2015.12. 025

Yamanda, S., Ebihara, S., Asada, M., Okazaki, T., Niu, K., Ebihara, T., et al. (2009). Role of ephrinB2 in nonproductive angiogenesis induced by Delta-like 4 blockade. Blood 113, 3631-3639. doi: 10.1182/blood-2008-07-170381

Yan, M., Callahan, C. A., Beyer, J. C., Allamneni, K. P., Zhang, G., Ridgway, J. B., et al. (2010). Chronic DLL4 blockade induces vascular neoplasms. Nature 463, E6-E7.

Yang, Q., Monticelli, L. A., Saenz, S. A., Chi, A. W., Sonnenberg, G. F., Tang, J., et al. (2013). T cell factor 1 is required for group 2 innate lymphoid cell generation. Immunity 38, 694-704. doi: 10.1016/j.immuni.2012.12.003

Yang, Z. J., Yu, Z. Y., Cai, Y. M., Du, R. R., and Cai, L. (2020). Engineering of an enhanced synthetic Notch receptor by reducing ligand-independent activation. Commun Biol. 3:116. 
Yen, W. C., Fischer, M. M., Axelrod, F., Bond, C., Cain, J., Cancilla, B., et al. (2015). Targeting Notch signaling with a Notch2/Notch3 antagonist (tarextumab) inhibits tumor growth and decreases tumor-initiating cell frequency. Clin. Cancer Res. 21, 2084-2095. doi: 10.1158/1078-0432.ccr-14-2808

Yeom, D. H., Lee, Y. S., Ryu, I., Lee, S., Sung, B., Lee, H. B., et al. (2021). ABL001, a Bispecific antibody targeting VEGF and DLL4, with chemotherapy, synergistically inhibits tumor progression in xenograft models. Int. J. Mol. Sci. 22:241. doi: 10.3390/ijms22010241

Yuan, J. S., Kousis, P. C., Suliman, S., Visan, I., and Guidos, C. J. (2010). Functions of notch signaling in the immune system: consensus and controversies. Annu. Rev. Immunol. 28, 343-365. doi: 10.1146/annurev.immunol.021908.132719

Yvon, E. S., Vigouroux, S., Rousseau, R. F., Biagi, E., Amrolia, P., Dotti, G., et al. (2003). Overexpression of the Notch ligand. Jagged-1, induces alloantigenspecific human regulatory T cells. Blood 102, 3815-3821. doi: 10.1182/blood2002-12-3826

Zhang, K., Xu, X., Pasha, M. A., Siebel, C. W., Costello, A., Haczku, A., et al. (2017). Cutting edge: notch signaling promotes the plasticity of Group-2 innate lymphoid cells. J. Immunol. 198, 1798-1803. doi: 10.4049/jimmunol.1601421

Zhang, W., Zhang, X., Sheng, A., Weng, C., Zhu, T., Zhao, W., et al. (2015). gamma-secretase inhibitor alleviates acute airway inflammation of allergic asthma in mice by downregulating Th17 cell differentiation. Mediators Inflamm 2015:258168.

Zhang, Y., Sandy, A. R., Wang, J., Radojcic, V., Shan, G. T. I, Tran, T., et al. (2011). Notch signaling is a critical regulator of allogeneic CD4+ T-cell responses mediating graft-versus-host disease. Blood 117, 299-308. doi: 10.1182/blood2010-03-271940

Zheng, H., Bae, Y., Kasimir-Bauer, S., Tang, R., Chen, J., Ren, G., et al. (2017). Therapeutic antibody targeting tumor- and osteoblastic niche-derived jagged 1 sensitizes bone metastasis to chemotherapy. Cancer Cell 32, 731.e6-747.e6.

Conflict of Interest: The authors declare that the research was conducted in the absence of any commercial or financial relationships that could be construed as a potential conflict of interest.

Copyright (C) 2021 Allen and Maillard. This is an open-access article distributed under the terms of the Creative Commons Attribution License (CC BY). The use, distribution or reproduction in other forums is permitted, provided the original author(s) and the copyright owner(s) are credited and that the original publication in this journal is cited, in accordance with accepted academic practice. No use, distribution or reproduction is permitted which does not comply with these terms. 